NASA Technical Memorandum 103243

AIAA-90-3681

\title{
A Technology Assessment of Alternative Communications Systems for the Space Exploration Initiative
}

Denise S. Ponchak, John E. Zuzek, Wayne A. Whyte, Jr., Rodney L. Spence, and Philip Y. Sohn

Lewis Research Center

Cleveland, Ohio

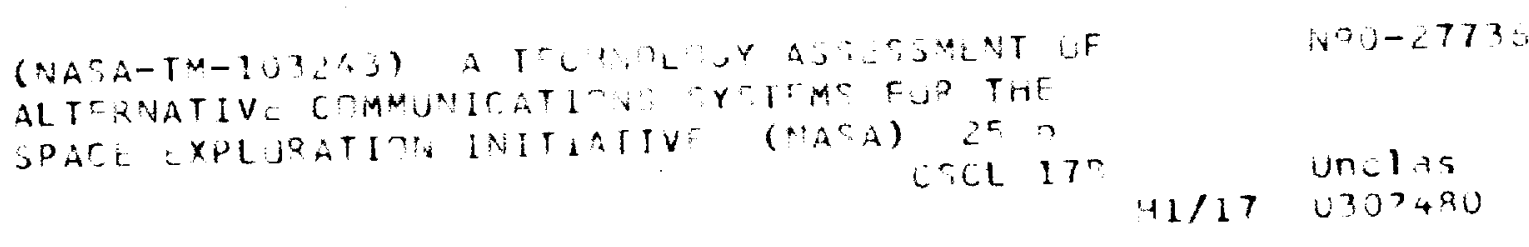

Prepared for the

Space Programs and Technologies Conference sponsored by the American Institute of Aeronautics and Astronautics Huntsville, Alabama, September 25-27, 1990 
n. 


\title{
A TECHNOLOGY ASSESSMENT OF ALTERNATIVE COMMUNICATIONS SYSTEMS FOR THE SPACE EXPLORATION INITIATIVE
}

\author{
Denise S. Ponchak*, John E. Zuzek*, Wayne A. Whyte, Jr., \\ Rodney L. Spence, and Philip Y. Sohn \\ NASA Lewis Research Center \\ Cleveland, Ohio
}

\begin{abstract}
1 Abstract
Telecommunications, Navigation, and Information Management (TNIM) services are vital to accomplish the ambitious goals of the Space Exploration Initiative (SEI). This paper provides a technology assessment of four alternative lunar and Mars operational TNIM systems based on detailed communications link analyses. The four alternative systems range from a minimum to a fully enhanced capability and use frequencies from S-band, through Ka-band, and up to optical wavelengths. Included are technology development schedules as they relate to present SEI mission architecture time frames.
\end{abstract}

\section{Introduction}

On July 20, 1989, President Bush provided the guidelines for a focused program that will achieve the objective of the 1988 Presidential Directive on National Space Policy: to expand human presence and activity beyond Earth orbit into the solar system. This outreaching program begins with the success of Space Station Freedom in the 1990's. The beginning of the new century sees a return to the moon and the establishment of a permanent manned lunar base. Then, the culmination of this ambitious program-the Space Exploration Initiative-takes us on a manned mission to our neighbor planet, Mars.

In order to accomplish the ambitious goals of the Space Exploration Initiative, four major infrastructure elements are vital: Launch Vehicles; Space Station Freedom; Surface Systems; and Telecommunications, Navigation, and Information Management (TNIM) services. The lunar and Mars TNIM systems provide data, voice, and image transmissions to communicate with manned mission elements, to monitor and control unmanned mission elements, to operate science experiments, and to provide radiometric data for navigation. ${ }^{1.2 .3}$ The objective of this paper is to highlight the major features of the preliminary TNIM systems and to identify the major enabling technology challenges.
Four options or levels of complexity will be presented for both the lunar and Mars operational TNIM systems. The first option provides the minimum TNIM capability necessary to support the manned mission elements. The objective is to provide a low cost system that requires little, if any, new technology development and does not require modification to NASA's Deep Space Network (DSN). The second option is a moderate upgrade from the first, keeping as a main objective low cost, but providing greater link capacity and increased connectivity. The third option is an evolutionary approach that fully meets all mission requirements as specified in earlier studies. Finally, the fourth option is a fully enhanced design that considers higher risk technology advances which provide the greatest amount of flexibility and growth capability.

Following the architecture definition is the assessment of technology needs to enable each TNIM option. In the telecommunications area, Ka-band (18-40 Ghz) communications technology has been identified to meet the mission requirements, while optical communications technology has been identified as an alternative if the data rate requirements were to increase significantly. ${ }^{4}$ Technology development required for the ground network to support the TNIM infrastructure is primarily focused towards conversion of the Deep Space Network (DSN) to a complete Kaband system. The current TNIM requirements and point designs contain data rates as high as $100 \mathrm{Mbps}$ for uncoded video and $1 \mathrm{Gbps}$ for astrophysics science instruments. This indicates a definite need for data compression and data storage to reduce the real-time data transmission rate. Unattended network operations, necessary to locate system failures and reconfigure the system appropriately, are vital for the success of the exploration missions.

Based on the assessment of technology needs for each option, a technology development schedule is presented and related to five different SEI mission architecture time frames.

Associate Member, AIAA 


\section{Alternative Architecture Definition}

In this section, an overview of the alternate TNIM architectures for the four options is presented along with a discussion of the advantages and disadvantages of each. A summary is presented in table 3-1, "TNIM Technology Options Overview".

The first option (Option-1) provides the minimum TNIM capability necessary to support the manned mission elements. The objective of this option is to provide a low cost system that requires little, if any, new technology development and does not require modification to the NASA Deep Space Network (DSN). Figure 3-1 presents an overview of this architecture. The major characteristics of Option-1 are that no relay satellites are employed in either the lunar or Mars TNIM systems. The lunar TNIM system supports only near-side communications and uses S-Band to support a $140 \mathrm{Mbps}$ return link to the DSN. The Mars TNIM system uses $\mathrm{X}$-band which can support a $250 \mathrm{kbps}$ return link and contact with mission elements on the Martian surface occurs only when the Mars Piloted Vehicle (MPV) or Earth is in view. This limits the system connectivity to less than $50 \%$. A modest amount of data compression and low volume data storage is utilized to reduce the data rate requirements. The Earth-based ground segment consists of the three DSN sites. The TNIM systems provide only Earth-based navigation.

The main advantage of the Minimum Capability Option is that it is the lowest cost option due to its simple concept. By not having relay satellites, this option also has the least impact on the overall mission design. Minimal technology development and little modifications to the DSN are necessary due to the selection of S-band and X-band. Though these advantages are directly beneficial from a cost point of view, Option-1 has a great number of disadvantages that may far outweigh any advantages. The first is the low data rate $(250 \mathrm{kbps})$ provided for Mars, which limits the video capability to still images. Science instruments are given low priority. The lack of relay satellites prohibits coverage of the far-side of the Moon and limits the coverage and connectivity available on the Mars surface. This in turn does not allow for alternative communications links for redundancy, for extra capacity, or in case of emergencies. The Earth-based network operations system has enormous manpower requirements which may offset any life-cycle cost savings achieved through the use of existing technology, and critical Earth stations are located outside the United States with associated costs.
The second option (Option-2) is a moderate upgrade from the first, keeping as a main objective low cost, but providing greater link capacity and increased connectivity. Figure 3-2 presents an overview of this architecture. The lunar TNIM system elements are the same as in Option-1, but the transmitter EIRP requirements are decreased by the use of higher $X$-band frequencies. The Mars TNIM system has increased capacity and connectivity over Option-1. The use of even higher Ka-band frequencies provide a $1 \mathrm{Mbps}$ return data rate, and the addition of a "bentpipe" Mars Relay Satellite (MRS) in the Mars TNIM system increases connectivity to $64-100 \%$. An increased amount of data compression and data storage is utilized to reduce the data rate requirements. Landing beacons are added, but navigation is still Earth-based.

This Moderate Upgrade Option is still a relatively simple concept thereby providing many of the same advantages as the first option (low cost and low impact on the mission design). The technology development necessary to enable this architecture is primarily for the Mars TNIM system which is implemented later in the SEI time frame, and the Ka-band upgrade required for the DSN is presently planned. Similar to the Option-1, this option provides only a modest return data rate from Mars (1 Mbps) which can sustain slow scan video. The lack of a lunar relay satellite prohibits coverage of the far-side of the Moon and coverage of the near Mars vicinity and surface is still less than 100 percent. With some unattended network operations functions, the manpower requirements are decreased, but not significantly. Also, critical Earth stations are still located outside the United States.

The third option (Option-3), shown in Figure 3-3, is an evolutionary approach that meets all mission requirements. Both the lunar and Mars TNIM systems operate at Ka-Band and employ relay satellites to increase surface coverage and connectivity. The main elements of the lunar TNIM system consist of orie Lunar Relay Satellite (LRS), one Lunar Surface Terminal (LST), near-side and far-side users, users in transit, users in Low Lunar Orbit (LLO), and the DSN. The LRS is placed in orbit about the $L 2$ libration point to support far-side users with communications among themselves and with links back to Earth. On the nearside, users within $10 \mathrm{~km}$ of the habitat are supported by the LST. User-to-user communications between far and near-side elements, within near-side users beyond the $10 \mathrm{~km}$ range, and with users in LLO and transit is completed via Earth relay. The main elements of the Mars TNIM system consist of two Mars Relay Satellites (MRS), distributed surface users, users in 
transit and orbit about Mars, users on the nearby moons (i.e., Phobos and Deimos), and the DSN. The two MRSs are inserted in Mars areostationary (analogous to geostationary) orbit $120^{\circ}$ apart to provide TDRSS type service. The relay satellites provide all intrasystem communications and the major communications links back to Earth. Full motion video transmissions from Mars are enabled by using 10:1 data compression and upgrading all three DSN sites to quad $34 \mathrm{~m}$ Ka-Band antenna subsystems. The emphasis in this option is on reliability and maintainability. Navigation is performed via an in situ network using landing and surface landmark beacons.

The advantages of the Full Upgrade Option are primarily related to capability as opposed to cost. The development cost for this TNIM architecture is roughly ten times greater than that of Option-1, but the Mars return data rate is capable of supporting full motion compressed video (10 Mbps). It fully supports science instruments, coverage of the lunar far-side is provided, and full coverage/connectivity is supported at Mars. With multiple relay satellites, alternate communications links are available in times of high demand or in case of emergency. Also, most network operation functions are unattended, which efficiently utilizes manpower and eliminates the potential for human error. Conversely, Option-3 cannot accommodate a large growth in data rate capability. It is a fairly complex system with three relay satellites, which would moderately impact the mission design. A moderate amount of technology development is required in the near future, and the necessary upgrade to the DSN is beyond what is presently being planned. Lastly, critical Earth stations are located outside the United States.

The final, or fourth option (Option-4) shown in figure 3-4 is a fully enhanced design that considers higher risk technology advances which would provide the greatest amount of flexibility and growth capability. This option includes all features of Option-3 plus an additional Lunar Relay Satellite (LRS). The second LRS is placed at the L1 libration point and provides a link between far-side and near-side users. It also provides coverage to distributed users on the nearside. Control of the system is fully automated, alleviating potential human error and providing automatic switching to redundant channels. Optical communications technology is considered as an alternative on the Mars return links to increase capacity and provide for system growth. The Earth-based portion uses a constellation of Geostationary Relay Satellites (GRS) that communicate to a single ground station within the United States.
Capacity, connectivity, and decreased delay are the main advantages of the Fully Enhanced Option. Use of an optical communication system has the potential to support a 100 Mbps return link from Mars. Science instruments are fully supported, and all elements of the mission are fully connected. The significant delay time encountered in the previous options for lunar farside to near-side communications has been virtually eliminated. Alternate communications links are available, as are alternate communications systems (RF and optical), for full redundancy, high priority needs, and emergency situations. Unattended network operations provide the greatest reliability possible. The last main advantage gained by using Earth relay satellites is that all Earth stations can be located in the United States. The disadvantages are its high cost and complexity. This option has the greatest technical challenges, and the technology development must be underway in the very near future.

\section{Link Analysis of the 4 Options}

In order to perform a meaningful technology assessment for the various options being examined, a detailed link analysis was performed for each of the identified lunar and Mars return links. The emphasis was on the analysis of the return links because the forward or outbound links from the Earth were assumed to be less critical technology drivers than the return links from the Moon and Mars. That is, building large antenna structures, extremely high power amplifiers, and very low noise receivers, for example, is far easier to do on Earth than in space. This is partially due to the fact that space qualification of the communications hardware is obviously unnecessary for use on the Earth's surface and kilowatts of power needed to run the system are more easily obtained.

\subsection{General Assumptions}

The various options utilize several different frequency bands for reasons cited in the descriptions of the individual options. For space-to-Earth links (i.e., those links from the lunar or Mars vicinity back to Earthbased receive terminals), frequency allocations ${ }^{5}$ for Space Research include S-band $(2200-2300 \mathrm{MHz})$, $X$-band $(8400-8500 \mathrm{MHz})$, Ka-band $(31.8-32.3 \mathrm{GHz})$, and $W$-band $(65-66 \mathrm{GHz})$. It should be noted that the Space Research frequency bands may not be able to be used for the return links from the Moon due to some regulatory problems concerning the definition of the Space Research service. However, these problems are being addressed and it is assumed that these frequency bands or at least bands close to 
these will be available for use in the lunar missions. Thus, the use of these bands for the purpose of this study is valid. For the space-to-Earth links for the Fixed Satellite Service (i.e., those links from a geostationary relay satellite to an Earth-based receive site as used in Option-4), the frequency allocation as used in this study is Ka-band $(19.7-21.2 \mathrm{GHz})$. Although any of the Fixed Satellite Service frequency bands could have been used for this purpose, the Ka-band allocation was chosen so that the desired high data rates could be achieved with the smallest antenna dimensions on the relay satellites and to be consistent with the other links. For intersatellite links (i.e., those links in Option-4 between the Mars Relay Satellites and the Geostationary Relay Satellites), the allocated frequency bands are Ka-band (22.55 $23.55 \mathrm{GHz}$ and 32 - $33 \mathrm{GHz})$, V-band $(54.25$ $58.2 \mathrm{GHz}$ and $59-64 \mathrm{GHz}$ ), and W-band (116 $134 \mathrm{GHz}$ ). In addition to these RF intersatellite frequencies, an optical frequency link between the Mars and Earth relay satellites was also considered in Option-4.

Where the path length of a given link varies, the worst case range is utilized. Thus, all distances from the lunar vicinity back to Earth were calculated with the Moon at its orbital apogee of $405,547 \mathrm{~km}$. The $\mathrm{L} 1$ and L2 libration points also vary with the Moon-to-Earth distance and are at a maximum at lunar apogee. The radius of the halo orbits ${ }^{6}$ around these libration points is taken to be $3500 \mathrm{~km}$ so that there will be no occultation of the $L 2$ relay satellite by the Moon as viewed from the Earth, including the possibility of minor orbital perturbations. The $\mathrm{L} 1$ relay satellite is assumed to be at the same halo radius and in the same phase as the L2 relay so as to allow simple connectivity. The Mars-to-Earth distance is assumed to be about $2.5 \mathrm{AU}$ (astronomical unit, where $1 \mathrm{AU}=1.496 \times 10^{8} \mathrm{~km}$ ) to be consistent with previous studies. In reality, this distance varies anywhere from $0.374 \mathrm{AU}$ to $2.675 \mathrm{AU}$ during the period from 1990 to 2039 as is illustrated in figure 4-1. The Mars Relay Satellite links to the Martian surface are based on the relay satellite being in areostationary orbit at a reasonable elevation angle to the surface terminals. The intersatellite link between the two Mars Relay Satellites in Option-3 and 4 is based on the satellites being separated by $120^{\circ}$ in orbit.

The observed background noise temperatures of the Earth, Mars, and the Moon are all assumed to be about $300 \mathrm{~K}$. In actuality, the observed temperature of the Earth ranges from 250 to $300 \mathrm{~K}$ and the observed temperature of Mars ranges from 210 to $300 \mathrm{~K}$, so the $300 \mathrm{~K}$ temperature represents a worst case possibility. On the other hand, the observed temperature of the Moon ranges from 120 to $390 \mathrm{~K}$ depending on whether the lunar surface is illuminated or not. In this case, a relative average value is utilized.

The Earth receive site ground terminal is assumed to have an elevation angle of approximately $10^{\circ}$ with respect to the Moon or Mars. This was derived by assuming that the hand-off point was approximately half way between the two DSN sites in question in both longitude and latitude. This angle is actually a minimum elevation angle which only occurs periodically. The elevation angle at any point in time may vary anywhere from about $10^{\circ}$ to about $70^{\circ}$ as is illustrated in figures 4-2 through 4-4.

The clear sky atmospheric losses due to oxygen and water vapor absorption for Earth recelve links were calculated using the methodology given in CCIR Report $719^{\circ}$. Rain attenuation for these links was calculated using the Crane Global Rain Modef with an availability of $95 \%$ for the Mars return links and $99.5 \%$ for all other links. The rain attenuation values were calculated for all sites using a $10^{\circ}$ elevation angle. The attenuation value utilized for the DSN receive sites is the maximum over all sites, the worst site being Canberra, Australia. However, reception of return signals will probably be shared fairly equally between the three DSN sites, assuming reasonably continuous transmissions. Further, the elevation angle varies over quite a wide range, as previously described, and is generally higher than the $10^{\circ}$ used in the calculations. Thus, the link availability will be much higher than the assumed $95 \%$ or $99.5 \%$ which was calculated on an absolute worst case basis.

All link calculations are based on an achieved bit error rate (BER) of $10^{-6}$. Space-based receivers are assumed to have a noise figure of $2.00 \mathrm{~dB}$ and feed losses of $1.5 \mathrm{~dB}$, except for the geostationary relay satellites. The DSN receiver noise figure is assumed to be $0.25 \mathrm{~dB}$ with feed losses of $0.1 \mathrm{~dB}$. Earth receive links are assumed to have a polarization loss of $0.2 \mathrm{~dB}$. Pointing losses are based on a pointing error which is $10 \%$ of the antenna half-power beamwidth for ground-based antennas and $15 \%$ of the beamwidth for space-based antennas. All of the demodulators on the lunar links across all options and the Mars Option-1 links are assumed to have a $3.0 \mathrm{~dB}$ implementation loss from theoretical. The remaining Mars links are assumed to achieve a $1.5 \mathrm{~dB}$ implementation loss in the demodulators.

The return link analysis was done assuming each return link was an independent link. In the case of a non-processing or bent-pipe satellite, this is clearly not 
true. Thus, for the non-processing links (i.e., the lunar links in Option-1,2, and 3 and the Mars links in Option-1 and 2), the return link is assumed to have been the result of one or more cascaded links and the return link performance is degraded by an amount commensurate with the number and quality of the cascaded links. For example, if the return link is the second of two equal links (i.e., two links with the same individual $\left.E_{b} / N_{b}\right)$, its performance is degraded by $3 \mathrm{~dB}$ to yield the correct end-to-end link performance. Additionally, all links are to achieve a link margin of $3 \mathrm{~dB}$. Summaries of the lunar and Mars link analysis are given in tables 4-1 and 4-2 respectively.

\subsection{Analysis of the Minimum Capability Option}

The Minimum Capability Option (Option-1) is meant to have little or no technology development. Thus, S-band frequencies are chosen for the lunar links and $\mathrm{X}$-band for the Mars links. There are only three basic lunar return links for this option. The Earth support is limited to the existing DSN with $26 \mathrm{~m}$ subnets for S-band. Using QPSK modulation and no forward error correction (FEC) coding, the main return data link from the Lunar Surface Terminal (LST) could only achieve a throughput of $140 \mathrm{Mbps}$ rather than the desired $200 \mathrm{Mbps}^{2}$ due to the bandwidth limitation of the S-band allocation. Although the rover and science instrument return links both achieve their required data rates of $20 \mathrm{Mbps}$ and $500 \mathrm{kbps}$ respectively ${ }^{2.3}$, they do so at the expense of rather high power demands for such space-based units $(170 \mathrm{~W}$ for the rover and $47 \mathrm{~W}$ RF power for the science instruments). The rover antenna is constrained to be $1 \mathrm{~m}$ or less and the science instruments are limited to antennas less than $0.3 \mathrm{~m}$.

The Mars return links for Option-1 are limited to $250 \mathrm{kbps}$ or less. Without any relay satellite in this architecture, both science instruments and rovers would have to communicate directly with the DSN on Earth. Alternatively, the Mars Surface Terminal (MST) and Mars Piloted Vehicle (MPV) can communicate with the Earth when it is within their field of view. The Earth support is limited to the existing DSN $34 \mathrm{~m}$ subnets for $X$-band. The links utilize QPSK modulation and are coded with concatenated interleaved rate $1 / 2$, constraint length 7 convolutional and Reed-Solomon $(255,223)$ error correction codes (RS/CONV). The limited data rates chosen for this architecture are achieved with reasonable power and antenna parameters for the MST (125 W, $4 \mathrm{~m}$ antenna) and MPV (80 W, $5 \mathrm{~m}$ antenna). However, the links from the rover and science instruments can only return $100 \mathrm{kbps}$ with very high power $(200 \mathrm{~W}$ and
$125 \mathrm{~W})$ and fairly large antenna sizes $(2.0 \mathrm{~m}$ and $2.5 \mathrm{~m})$ for such small space-based units. Additionally, without any relay satellites, there is only limited coverage in the Mars vicinity with connectivity ranging from 2 to $43 \%^{3}$ due to various occultations between nodes.

\subsection{Analysis of the Moderate Upgrade Option}

The Moderate Upgrade Option (Option-2) allows for moderate technology development and a small increase in architectural complexity. The lunar return links utilize a higher frequency band, $X$-band, and the Mars return links utilize Ka-band with $X$-band examined as a possible alternative for return links back to Earth. The lunar return links employ QPSK modulation. The return link from the LST uses no FEC and achieves a data throughput of $140 \mathrm{Mbps}$ rather than the desired $200 \mathrm{Mbps}$ due to the bandwidth limitation of the X-band allocation. The return links from the rover and science instruments with rate $1 / 2$ convolutional coding achieve the desired data rates of $20 \mathrm{Mbps}$ and $500 \mathrm{kbps}$ respectively with power levels less than $3 \mathrm{~W}$. The Earth support consists of the present DSN upgrade of $34 \mathrm{~m} \mathrm{X}$-band subnets. The upgrade from S-band to $X$-band allows the transmitter power levels and antenna sizes to be cut back to more reasonable values than those in Option-1.

In Option-2, the Mars architecture has a single Mars Relay Satellite (MRS) in areostationary orbit which acts as a simple in-orbit repeater. Additionally, the primary return link frequency has been upgraded from $X$-band to Ka-band. The return link from the MRS requires a data throughput of $1 \mathrm{Mbps}$ by design, which is much higher than the Option-1 Mars return links. The Earth support consists of the present DSN upgrade to $34 \mathrm{~m}$ Ka-band subnets. The Mars links use QPSK modulation with the same RS/CONV coding as in Option-1. With a $5 \mathrm{~m}$ antenna, the MRS requires $400 \mathrm{~W}$ of RF power to return a single $1 \mathrm{Mbps}$ channel at Ka-band. With a $7.8 \mathrm{~m}$ antenna on the MRS, the RF power requirement could be reduced to $200 \mathrm{~W}$. As an alternative, the use of $\mathrm{X}$-band was also considered for the MRS-to-Earth return link. This link achieves the $1 \mathrm{Mbps}$ data rate with the same $200 \mathrm{~W}$ of RF power and a slightly smaller $7.1 \mathrm{~m}$ antenna. The reason that the X-band link performs about the same or even slightly better than the higher frequency, higher gain Ka-band link is due to the consideration of rain attenuation. For the same availability, the rain attenuation at Ka-band is much higher than that at $\mathrm{X}$-band. The additional attenuation also has a warming effect on the receive system noise temperature which further degrades the comparative 
performance of Ka-band with respect to X-band. It should be noted, however, that in contrast to the analysis done in this study which is based on worst case assumptions (i.e., the elevation angle is generally much better than the $10^{\circ}$ used herein, the reception of signals is actually shared between multiple sites rather than taking place exclusively at the "worst" site, etc., as described in section 4.1), Ka-band will actually suffer less attenuation and perform better than $\mathrm{X}$-band for the desired overall availability of these links. Due to the presence of the relay satellite and the use of Ka-band frequencies, much more data can be transferred in the vicinity of Mars. For example, the MST, rovers, and science instruments can achieve data rates of $20 \mathrm{Mbps}, 10 \mathrm{Mbps}$, and $500 \mathrm{kbps}$ respectively with transmit powers no more than $7.9 \mathrm{~W}$ $\mathrm{RF}$ and antennas no larger than $3 \mathrm{~m}$ in diameter. $\mathrm{A}$ further advantage of the relay satellite is increased coverage around Mars and connectivities ranging from 64 to $100 \%^{3}$ which are a vast improvement over those achieved in the Option-1 architecture.

\subsection{Analysis of the Full Upgrade Option}

The Full Upgrade Option (Option-3) allows for a further increase in both complexity and technology development. The lunar return links utilize Ka-band frequencies and provide far-side coverage via a simple repeater relay satellite in a halo orbit around the translunar libration point, L2. The L2 lunar Relay Satellite (LRS) provides return links from the far-side of the Moon to the Earth receiving stations. The LST, rovers, and dispersed science instruments on the near-side communicate directly with Earth stations. For far-side transmissions to be routed to the nearside vicinity, the signals must travel back to Earth and be retransmitted to the near-side terminal with a total one-way transmission delay of about 3 seconds. All links use QPSK modulation and the RS/CONV coding for FEC, which is possible due to the additional bandwidth which would be available at Ka-band. In contrast, $\mathrm{X}$-band was also examined as an alternative for several of the return links, but such links are bandwidth limited and cannot utilize FEC coding thereby requiring significantly higher transmitter powers. The Earth support is assumed to be comprised of a proposed upgrade to the DSN using Ka-band $70 \mathrm{~m}$ subnets for lunar support.

The far-side LST achieves a throughput of $100 \mathrm{Mbps}$ to the L2 LRS with only a $1 \mathrm{~m}$ antenna and $5.6 \mathrm{~W}$ of RF power at the LST and a $2 \mathrm{~m}$ antenna on the LRS. By contrast, using $X$-band requires a $2 \mathrm{~m}$ antenna and $60 \mathrm{~W}$ of RF power at the LST to get the same throughput, which illustrates the advantage of Ka-band in the lunar vicinity. The L2 LRS picks up additional data from dispersed far-side sources to return $125 \mathrm{Mbps}$ to the Earth with only a $2 \mathrm{~m}$ antenna and $3 \mathrm{~W}$ of transmit power. Even with the higher attenuation near Earth of Ka-band, a comparative $\mathrm{X}$-band link performs worse than the Ka-band link due to the lack of coding. The near-side science instruments, rovers, and LST all achieve their desired data rates ranging from $500 \mathrm{kbps}$ to $200 \mathrm{Mbps}$ with reasonable powers and antennas less than $0.4 \mathrm{~m}$. In addition to the traffic model data $a^{2}$ used in these analyses, it was found that there may be a real need for returning data at rates of about 1 Gbps from some potential far-side astrophysics instruments ${ }^{10}$. Such a data rate could easily be supported using Ka-band from the far-side LST through the L2 LRS with $56 \mathrm{~W}$ transmitters at the far-side LST and $23.5 \mathrm{~W}$ transmitters on the L2 LRS using the same 1 and $2 \mathrm{~m}$ antennas as before. The main problem in achieving such a data rate is probably regulatory in that sufficient bandwidth needs to be allocated for this purpose.

The Mars Option-3 architecture includes two areostationary Mars Relay Satellites which are processing satellites or regenerative repeaters. Ka-band is utilized for the primary return link frequencies as in Option-2. The Earth support consists of the proposed DSN upgrade to Ka-band $70 \mathrm{~m}$ subnets for Mars support. Coherent 8 -FSK is used as the power efficient modulation scheme in addition to the RS/CONV coding for FEC on the Mars-to-Earth return links. The local Mars links are not power limited so they can use the simpler rate $1 / 2$, convolutional code for FEC which simplifies the CODEC design. Additionally, the required data rate on the Mars-to-Earth return link is now raised from $1 \mathrm{Mbps}$ in Option-2 to $10 \mathrm{Mbps}$ per channel in this option. The MRS to Earth Ground Terminal (GT) link is the most critical as it was in Option-2. Using a $9 \mathrm{~m}$ MRS antenna, a $180 \mathrm{~W}$ transmitter is required to achieve the desired data rate. For an X-band link with a $9 \mathrm{~m}$ MRS antenna, a $135 \mathrm{~W}$ transmitter is required for the same data rate. Similarly, if the MRS antenna is constrained to $5 \mathrm{~m}$, then a $182 \mathrm{~W}$ transmitter could return only $3.8 \mathrm{Mbps}$ to the GT. The links in the vicinity of Mars, which include a crosslink between relay satellites, achieve their requisite data rates ranging from $500 \mathrm{kbps}$ to $50 \mathrm{Mbps}$ with transmit powers of $6.6 \mathrm{~W}$ or less and antennas of $1 \mathrm{~m}$ or less. The addition of the second relay satellite increases coverage to near $100 \%$ and provides continuous connectivity ${ }^{3}$ except when Mars is occulted by the Sun. 


\subsection{Analysis of Fully Enhanced Option}

The major differences between the Fully Enhanced Option (Option-4) and Option-3 are the addition of a lunar relay sateliite in a halo orbit about the $L_{1}$ libration point on the near-side of the Moon and the use of Geostationary Relay Satellites (GRS) to receive signals from both the Moon and Mars rather than direct reception on the Earth's surface. In addition, the use of the GRS also allows higher RF frequencies and optical frequencies to be examined as alternatives for the Mars return links since atmospheric losses and rain attenuation are no longer a consideration. The total data throughput of the lunar return links is increased to $350 \mathrm{Mbps}$ in this option. The L1 LRS reduces the delay time for transmissions from the farside to the near-side to well under one second, greatly enhancing connectivity in the lunar vicinity. The near-side LST uses a $2 \mathrm{~m}$ antenna and a $42 \mathrm{~W}$ transmitter to return $350 \mathrm{Mbps}$ to the GRS. The GRS can relay the $350 \mathrm{Mbps}$ down to either a DSN complex, a complex like White Sands (TDRSS/ATDRSS), or something comparable with less than a $2 \mathrm{~W}$ transmitter and with an antenna of 0.5 to $1 \mathrm{~m}$ in diameter depending on the size of the Earth receive antenna. As in Option-3, data rates in the $1 \mathrm{Gbps}$ range were also examined. These links require a $26.5 \mathrm{~W}$ transmitter on the L2 LRS, a $5.5 \mathrm{~W}$ transmitter on the L1 LRS, and a $52 \mathrm{~W}$ transmitter on the near-side LST to achieve such data rates, once again with the caveat about the regulatory requirements on bandwidth.

All of the local Mars links are the same as those in Option-3. The MRS-to-GRS return links are assumed to utilize coherent 16-FSK with the RS/CONV coding for FEC. This yields an MRS with a $5 \mathrm{~m}$ antenna and a $110 \mathrm{~W}$ transmitter and a GRS with a $36 \mathrm{~m}$ antenna to return the required $10 \mathrm{Mbps}$ using Ka-band. With a $10 \mathrm{~m}$ antenna on the MRS, the GRS antenna reduces to $20 \mathrm{~m}$. At the higher $R F$ frequencies of $60 \mathrm{Ghz}, 94 \mathrm{GHz}$, and $134 \mathrm{GHz}$, if the MRS uses transmitter powers of 110 to $115 \mathrm{~W}$ and a $10 \mathrm{~m}$ antenna, the results are GRS antennas of 15, 12, and $11 \mathrm{~m}$ respectively with various assumptions on the higher frequency component parameters.

Two 100 Mbps optical link implementations for the MRS-to-GRS return link were analyzed: a direct detection (DD) link using Binary Pulse Position Modulation (BPPM) and a homodyne detection link using BPSK. In the latter, homodyne detection was selected over heterodyne detection since it theoretically has the highest detection sensitivity. The transmitting laser in both cases was a diode-pumped Nd:YAG (Neodymium:Yttrium Aluminum Garnet) laser operating at the frequency-doubled wavelength of $0.532 \mu \mathrm{m}$. Because of the extremely small beamwidths involved, spatial tracking and pointing errors must be carefully considered in the design of the optical communication link. In a real environment the tracking and pointing errors will not be fixed or static. Rather, because of the relative motion of the two spacecraft, tracking sensor noise, platform vibration, telescope gimbal friction, and errors in point-ahead calculation, the instantaneous transmitter pointing error will fluctuate randomly in time. For the link analyses performed here, a practical spatial tracking system using a quadrant APD (Avalanche Photodiode) tracking photodetector and having small closed-loop (noise-equivalent) bandwidth was assumed.

The fact that the pointing/tracking error is a random process is very important, since it means that link performance (i.e., BER) does not improve without limit as aperture size increases. Instead, for a given value of RMS pointing/tracking jitter, there exists an optimum transmit aperture size (and also receive aperture size for the heterodyne/homodyne system) which minimizes the transmit laser power requirement. Furthermore, because the dominant source of pointing/tracking error is on-board mechanical vibration of the satellite and not tracking detector noise, the pointing/tracking error cannot be reduced by simply increasing the transmit power to improve the SNR.

Link designs which minimize the transmit laser power requirement for the two optical implementations in the presence of Rayleigh distributed random pointing/tracking errors were computed. These links were sized to just meet the average received power requirement for a $10^{-6}$ average BER (i.e., zero link margin). The RMS pointing/tracking errors were chosen so as to yield "realizable" laser transmit power levels.

With $0.1 \mu$-radian RMS pointing jitter, the BPPM DD link has a minimum power requirement of $15.8 \mathrm{~W}$ (average power) using an optimum transmit aperture size of $80 \mathrm{~cm}$ and a $10 \mathrm{~m}$ receive aperture. Operation at $100 \mathrm{Mbps}$ would require the $\mathrm{Nd}: \mathrm{YAG}$ laser to operate in a cavity-dumped mode with a required peak power of about $32 \mathrm{~W}$. The optimum transmit aperture size and corresponding minimum power requirement for different values of the RMS pointing jitter can be computed. For example, $0.05 \mu$-radian RMS jitter yields an optimum transmit aperture size of $1.6 \mathrm{~m}$ and a minimum average power of $4 \mathrm{~W}$. A $0.5 \mu$-radian RMS value, on the other hand, gives an aperture diameter of $16 \mathrm{~cm}$ and a power requirement 
of almost $400 \mathrm{~W}$. The sensitivity of the optical link to the random pointing and tracking error is therefore apparent.

Heterodyne and homodyne optical systems are even more sensitive to spatial tracking errors, since they affect not only the pointing accuracy of the transmitting laser, but also the beam alignment between the received signal and the local oscillator (LO) laser. Consequently, for these systems, both the transmit and receiver aperture sizes are constrained and there exists optimum values for each which minimize the required transmit laser power. An optimized link budget for the 100 Mbps homodyne PSK system, assuming an RMS pointing and LO alignment error of $0.05 \mu$-radian, was computed. The optimum aperture sizes are $1.8 \mathrm{~m}$ and the minimum power requirement is $11.8 \mathrm{~W}$ (average power). It should be noted that the homodyne link has an $11 \mathrm{~dB}$ detection sensitivity advantage over the BPPM DD link for the same BER (i.e., $-96 \mathrm{dBW}$ vs. $-85 \mathrm{dBW}$ ). Because of the LO tracking error, however, the pointing/tracking loss is about $2.4 \mathrm{~dB}$ higher. Like the DD link, the homodyne link is very sensitive to the pointing/tracking error. For RMS error of 0.1 $\mu$-radian, the value used for the DD link, the optimum transmit and receive aperture size is reduced to 90 $\mathrm{cm}$ and the required laser power increases to $190 \mathrm{~W}$. an unacceptably high value. Therefore, the advantage of higher detection sensitivity of heterodyne and homodyne systems is only valid when the pointing and tracking jitter is extremely small.

The optical link analysis described here assumes no channel coding. The application of error control schemes to correct for burst errors could considerably reduce the transmit power requirements. For example, the use of the RS/CONV coding for the PSK homodyne link could provide about $8.2 \mathrm{~dB}$ of coding gain at $10^{-6} \mathrm{BER}$. This would reduce the power requirement from $11.8 \mathrm{~W}$ to $1.8 \mathrm{~W}$. It should be noted, however, that in order for a particular coding scheme to be effective, the RMS error must be small enough to ensure that the instantaneous $B E R$ at the input to the decoder is below the code threshold $B E R$, typically about $10^{-2}$, a large fraction of the time.

\subsection{Link Analysis Issues}

There are several relevant issues regarding the link analysis performed for this study that merit discussion. First, the worst case analysis approach may lead to conclusions about power levels and antenna sizes that overstate technology requirements. If the Mars return links are designed for the $2.5 \mathrm{AU}$ distance, there is approximately a $14 \mathrm{~dB}$ gain in link margin when the Earth and Mars are only 0.5 AU apart. This net gain could realistically be used to increase the data throughput for a given availability or to increase the link availability for a given data rate. Of course, as has been stated previously, the availability issue is not that straightforward since the receive site changes about three times in any 24 hour period and the elevation angle changes continuously for each site over its period of reception. Additionally, site diversity could be utilized to further increase the link availability. Thus, the availability problem is not nearly as severe as the analysis herein has indicated. A more exact answer to the avallability question is ultimately needed, but such an investigation is beyond the scope of this study.

Several comparisons of $\mathrm{X}$-band and Ka-band have been done for return links to Earth and the indications were that the X-band links actually performed about the same as the Ka-band links. Once again, this is a worst case scenario. If we compare the two frequency bands for clear sky transmissions (i.e., providing no margin for rain attenuation), Ka-band has a substantial advantage over $X$-band. If reception is compared at the DSN sites, Ka-band picks up almost a $10 \mathrm{~dB}$ margin under clear sky conditions versus almost no change for $\mathrm{X}$-band. Reality is somewhere in between these two cases indicating that Ka-band does hold a definite advantage over X-band. Complete details on the assumptions used in the link analysis as well as the detailed link budgets for all of the links examined can be found in the reference report ${ }^{11}$.

Finally, the half-power beamwidths of the $34 \mathrm{~m}$ and $70 \mathrm{~m}$ DSN antennas at Ka-band are a very small fraction of the angle subtended by the Moon and the halo orbits. Even if the DSN antenna can scan about 10 beamwidths, a single beam cannot cover the necessary nodes in the lunar vicinity. Thus, multiple antennas may be required at each site to provide adequate coverage of the lunar missions. Also, some consideration needs to be given to the hand-off from one DSN site to the next. In some cases, it may be necessary to use multiple antennas at the LST to cover the hand-off.

\section{Technology Assessment}

Based on the examination of the four alternate telecommunications architectures and the analysis of their respective communications links, technology needs for telecommunications and information management were determined as a function of user application. An assessment of these technology needs has determined the required technologies to 
enable these options, the present applications of the technologies, the present state-of-the-art of the technologies (excluding classified military projects), and the maturity of the technologies ${ }^{4}$. The maturity of the technologies is expressed in terms of the standard NASA Technology Readiness Levels (TRL), shown in table 5-1. In some cases, alternate technologies were identified. A summary of the RF technology assessment for the four options is shown in table 5-2. Further details concerning the specific technologies (RF, optical, and information management) are discussed in the following subsections. Navigation technology needs were not addressed in this study.

\subsection{Option-1 Technology Assessment}

The main objectives of Option-1 are low cost and the use of existing technology wherever possible. The resultant technology assessment shown in table 5-3 verifies these objectives. Very few technologies require development, and what is required is not extensive. To support the lunar TNIM system, technology development is required in the areas of advanced modulation and coding, and high-power Sband traveling wave tube amplifiers (TWTAs). The need for advanced modulation and coding to achieve $2 \mathrm{~b} / \mathrm{s} / \mathrm{Hz}$ is due to the limited bandwidth available at S-band $(100 \mathrm{MHz})$ coupled with the high data rate requirements. A coded 8-PSK modulator/ demodulator capable of $2 \mathrm{~b} / \mathrm{s} / \mathrm{Hz}$ has been demonstrated in the laboratory environment, corresponding to a technology readiness level of 4 , and could be ready for the SEI missions with a small focused effort. The need to minimize rover antenna diameters to less than $1 \mathrm{~m}$ and the requirement to communicate directly back to Earth, produced the need for a $170 \mathrm{~W}$ S-band TWTA. S-band TWTAs have been successfully flown numerous times in space, but primarily at lower power levels than that required by a lunar rover. A $150 \mathrm{~W}$ S-band TWTA was flown on shuttle, but the collector design was extremely inefficient. With today's knowledge, a modest development program could produce a newly designed TWTA with higher power and greater DC-RF efficiency.

The Mars TNIM system for Option-1 requires large antennas and high-power transmitters for all data links returning to Earth. Using $X$-band frequencies with 5 $\mathrm{m}$ antennas and 80-200 W TWTAs (depending on the application) allows the return of a modest $250 \mathrm{kbps}$. High-power $\mathrm{X}$-band TWTAs have been primarily designed for ground station applications and technology development in this area would be primarily focused on space-qualification. Also, large $X$-band antennas have not been demonstrated in space. The present maturity level is between 3 and 4 based on the TDRSS $5 \mathrm{~m}$ S-band single access antenna. Further development in both the areas of deployable (mesh and inflatable) and solid precision reflector antennas is necessary.

\subsection{Option-2 Technology Assessment}

The technologies required to support Option-2 are shown in table 5-4. Minimal technology development is required to support the lunar TNIM system since it uses established $\mathrm{X}$-band technology and the lunar distances do not impose large EIRP requirements on the transmitter. Additional development is necessary only in the area of advanced modulation and coding to support the high lunar return data rates. With only $100 \mathrm{MHz}$ of bandwidth available at X-band, space qualified hardware (modulators and demodulators) for bandwidth efficient techniques must be developed as in Option-1.

The majority of technology development for this option is to support the Mars TNIM system. This is a direct function of the increased return data rate requirements necessitating a move to the higher, less developed Ka-band frequencies. Since the architecture concept is fairly simple, most of the development is primarily focused at modifying and redesigning existing technologies to operate at Ka-band. Technology development costs for Mars missions can be spread over a longer period than those to support lunar missions since the Mars missions occur later in the SEI time frame. TNIM system costs for Option-2 will remain relatively low.

Specific technologies required to enable the Mars TNIM system for Option-2 primarily focus on the relay satellite antenna and transmitter characteristics. Large reflector antennas on the order of 5-8 $\mathrm{m}$ with high powered TWTAs (> $200 \mathrm{~W}$ RF) are required to provide enough gain to support $1 \mathrm{Mbps}$. These large antennas impose a very stringent pointing requirement for the Mars relay spacecraft on the order of 0.01 degrees. With the changing geometrical relationships, some antennas will have to be able to rotate or swivel a complete 360 degrees. These technologies are the most important in providing the vital link between Earth and the astronauts, and they are also the least technologically advanced (TRL-2). The largest antenna flown to date is the $30 \mathrm{ft}$ solid/mesh hybrid on-board ATS-6. The highest frequency of operation for this fixed earth-pointing antenna was $\mathrm{C}$-band $(6 / 4 \mathrm{GHz})$. The Mars surface coverage antennas have to support a broad range of system elements in many diversified locations. This will require multibeam antennas to serve the local 
environment, with a capability of $\sim 10$ switched beams. NASA's Advanced Communications Technology Satellite (ACTS), scheduled to be launched in 1992, will demonstrate such an antenna system. Low power Ka-band Solid State Power Amplifiers (SSPA) are required to support rovers and science instruments located on the surface due to their smaller weight/volume characteristics and lower DC power consumption compared to TWTAs. This technology is relatively immature since there have not been any space applications to date for SSPAs in this frequency band.

Finally, with the increase in frequency and data rates, there is a need for advanced Ka-band ground station equipment. Large $34 \mathrm{~m}$ antennas with low surface tolerances, $0.25 \mathrm{~dB}$ low noise receivers, and low loss demodulators are required to support the $1 \mathrm{Mbps}$ Mars return data link. This development is already underway and will primarily need funding to advance it to the implementation phase.

\subsection{Option-3 Technology Assessment}

The technology assessment for Option-3 is summarized in Table 5-5. Option-3 represents a full upgrade to Ka-band frequencies for both the lunar and Mars TNIM systems. This upgrade fully meets all current mission requirements, supporting data rates as high as $325 \mathrm{Mbps}$ for the major lunar return link and multiple $10 \mathrm{Mbps}$ return links from Mars. To date, the upper $30 \mathrm{GHz}$ region of the Ka-band is relatively unused and substantial bandwidth is available. This in turn implies that significant technology development is required. An assessment of the technology development required to support this option has shown that the majority of such development would be classified as low to moderate risk, and similarities between the lunar and Mars TNIM systems allows for the use of the lunar phase as a testbed for the distant Mars systems.

The full upgrade lunar TNIM system includes a far-side lunar relay satellite to increase surface coverage and improve system interconnectivity. This satellite must be able to communicate with system elements widely spread across the lunar far-side surface, while maintaining continuous contact with Earth. These surface elements will have different operational requirements such as time and duration of operation and data rate. In addition, the satellite orbits about the $L 2$ libration point and its precise altitude above the Moon's surface is constantly changing. This places unique constraints on the design since the satellite must be able to track elements on the surface, and the surface coverage must be accurately maintained.
In order to maintain constant contact with Earth, the $2 \mathrm{~m}$ Earth-facing antenna must be able to rotate 90 degrees. This is beyond the present TDRSS capability and that which will be demonstrated in 1997 with the first launch of the ATDRSS system. An initial assessment of the far-side users has concluded that a multibeam antenna capable of switching between 10 beams could satisfy the initial communications needs. Two alternate technologies were identified to satisfy this need. The first is a fixed beam concept similar to the antenna system to be flown on ACTS in 1992. The ACTS antenna feed system employs horn radiators to generate the individual fixed spot beams. An alternative technology that is less developed is an MMIC phased array feed system. By remotely varying the phase of the individual amplifiers, beam locations can be moved to meet the changing needs of the mission. This type of feed system can also be used to maintain surface coverage with the varying satellite altitude. An MMIC phased array feed system is much less developed than feed horns, and it is further complicated with system integration constraints. At the component level, MMIC receive and transmit modules need to be developed that are lower in noise and higher in power than those previously developed, and that operate in the $30 \mathrm{GHz}$ region of Ka-band. Integrating these modules into a full scale system also must be demonstrated. Issues such as MMIC packaging and characterization, printed circuit elements, array control, power dissipation, RF distribution, and others must all be investigated prior to space qualification.

All lunar return links have transmitting power levels that can best be achieved using TWTA technology. High efficiency TWTAs in the 10 to $55 \mathrm{~W}$ range are presently at a TRL-3. Their counterpart, SSPAS, are most suited for science instrument communications packages and are presently at a technology readiness level of 2.

The full upgrade Mars TNIM system includes two processing areostationary satellites to increase surface coverage, interconnectivity, and system capacity. Since the frequency for the Mars links in Option-3 is the same as that used in the Option-2 Mars TNIM system and the Option-3 lunar TNIM system, much of the technology development is the same: $5-9 \mathrm{~m}$ Ka-band S/C reflectors; $360^{\circ}$ mechanically steerable reflectors; 10-beam electronically switched fixed beam antennas; 10 -beam electronically steered phased array antenna; $0.01^{\circ} \mathrm{S} / \mathrm{C}$ pointing accuracy; Ka-band SSPAs; and, MMIC devices. In addition to these, two new areas require development. In order to help reduce the tremendous power requirements on the Earth return link, use of a 
power efficient modulation scheme (8-FSK) was assumed. Coherent 8-FSK modulation was selected because it provides a modest power advantage and it is less complex than higher order schemes. This area of technology is relatively underdeveloped. Present geostationary satellite systems primarily use phase modulation to reduce bandwidth constraints and are not concerned with power due to the comparatively short distances involved. Mars communications systems require just the opposite. Bandwidth should be available while excess power is not. Ka-band TWTAs will still need development to support Option-3, but the power requirements have been relaxed somewhat $(115 \mathrm{~W})$ due to the use of power efficient modulation and $70 \mathrm{~m}$ receive antennas. Finally, baseband processing and switching has been included to reduce system noise and to provide the degree of flexibility in system configuration required by human settlements. An initial requirement for baseband processing at the level of the ACTS satellite was deemed sufficient and could be ready in the necessary time frame. ACTS will demonstrate baseband processing and switching in the 1992 time frame.

Finally, with the increase in frequency, there is a need for advanced Ka-band ground station equipment at each of the three DSN sites. Large, quad $34 \mathrm{~m}$ antennas (to achieve an effective $70 \mathrm{~m}$ aperture) with low surface tolerances, $0.25 \mathrm{~dB}$ low noise receivers, and low loss demodulators are required to support the 10 Mbps Mars return data link. This development is part of the long range plan and will require significant funding, primarily to install the twelve $34 \mathrm{~m}$ antennas.

\subsection{Option-4 Technology Assessment}

Option-4 represents a fully enhanced TNIM system that takes advantage of leading edge technology and beyond to provide the greatest system capability in terms of capacity, connectivity, reconfigurability, and the ability to accommodate changing needs. This is accomplished by the use of processing relay satellites around the Earth as well as the Moon and Mars. The baseline frequency is the same as that of Option-3, but alternate higher frequencies and optical communications are also examined where their use may accrue benefits. This results in the need for the same technology development as in Option-3 and additional development for the technology requirements resulting from the alternate frequencies and the increased system capability. A summary of RF technology development for Option-4 is given in table 5-6, and a discussion of optical technology is given later in this section.
An examination of table 5-6 for the lunar TNIM system shows that the majority of the technology development required is inclusive of what was required for Option-3: mechanically steerable reflector, electronically switched fixed beam antenna, electronically steered phased array antenna, reconfigurable antennas, Ka-band TWTAs, Ka-band SSPAs, and MMIC devices. The requirement on these technologies is similar to Option-3 except for the case of the alternate multibeam concepts. It was determined that Option-4 would be configured to support a greater number of system users and would therefore need on the order of 20 spot beams. This is not a challenging increase in the case of the fixed beam concept, but for the phased array concept this increased requirement translates into an exponential growth in developmental effort. Other technology areas requiring development result from the introduction of baseband processing and advanced coding to alleviate power requirements on the individual system users. Neither of these areas will pose a great technology challenge with both having a technology readiness level of 4 . Baseband processor requirements on the order of the ACTS capability are sufficient and the concatenated Reed/Solomon coding/decoding hardware mainly requires space-qualification and demonstration. The final area of technology development for the lunar TNIM System results from the integration of the geostationary relay satellites into the system architecture. In the previous options, the signal was received on the ground with extremely large antennas and now this capability must be placed in orbit. However, due to all of the system enhancements, this can be achieved with a moderate development effort to produce a receiving subsystem consisting of a $5 \mathrm{~m}$, $55 \%$ efficient Ka-band spacecraft antenna, a $0.4 \mathrm{~dB}$ low loss feed system, and a low noise Ka-band receiver with a $0.5 \mathrm{~dB}$ noise figure (NF). The most challenging of these may be the low loss feed system, since present systems do not achieve levels in this range, which places it at a technology readiness level of 1 .

The architecture of the Option-4 Mars TNIM system is the same as Option-3 with respect to the Mars vicinity, and therefore technology development for Option-4 includes all development outlined for Option-3. The major differences between Option-3 and Option-4 occur in the near Earth region. With the addition of a dedicated geostationary satellite constellation, higher frequency RF systems and optical systems have been examined for the Mars return link since the signal does not have to penetrate the atmosphere to reach the primary receiver. Higher order modulation 
(16-FSK) and coding were also included to alleviate the power burden to the remote system users.

Technology development to support the RF systems directly focuses on the transmitters and receivers. In order to minimize the spacecraft antennas on both ends of the return link (MRS and GRS), based on a parametric tradeoff of antenna gain and power, the RF output power of the traveling wave tube amplifiers was fixed at $115 \mathrm{~W}$. The technology maturity for TWTAs at these frequencies and at this power level is fairly low, since these bands have had no prior use, other than possible military applications. The TRL ranges from 1 to 2, with 2 representing the lower bands (Ka-band and $60 \mathrm{Ghz}$ ) and 1 representing the higher bands ( $94 \mathrm{GHz}$ and $134 \mathrm{GHz}$ ). On the receiving end of the link, development is required in the area of low noise receivers. This assessment concluded that to minimize antenna dimensions, noise figures as low as $0.5 \mathrm{~dB}$ would be required for Ka-band, ranging up to $2.0 \mathrm{~dB}$ for $134 \mathrm{GHz}$. Technology readiness levels for these receivers were assessed to be the same as for the amplifiers. Other areas requiring technology development in order to sustain these links include the signal processing equipment and the spacecraft antenna systems. Technologies related to the signal itself include coherent 16-FSK modulation and RS/CONV coding to relieve the power burden on the MRS transmitter. Based on presently funded laboratory work and existing hardware, both of these technologies were assessed to be at a technology readiness level of 4 .

By placing the DSN capability in orbit, large high gain antennas are required on both ends of the link. Antennas of $5 \mathrm{~m}$ and $10 \mathrm{~m}$ diameter were examined for the MRS. With a $5 \mathrm{~m}$ antenna and 110-115 W transmit power, a $36 \mathrm{~m}$ GRS antenna is required to support the $10 \mathrm{Mbps}$ data rate. Increasing the MRS antenna size to $10 \mathrm{~m}$ reduces the GRS antenna size to $20 \mathrm{~m}$. At $60 \mathrm{GHz}, 94 \mathrm{GHz}$, and $134 \mathrm{GHz}$, a $10 \mathrm{~m}$ MRS antenna yields GRS antenna sizes of $15 \mathrm{~m}, 12$ $m$, and $11 \mathrm{~m}$, respectively. These large antennas represent a significant technical challenge. As mentioned previously, the largest antenna flown to date is the $30 \mathrm{ft}(9.14 \mathrm{~m})$ ATS- 6 antenna operating at C-band. The largest Ka-band antenna developed to date is the $3.2 \mathrm{~m} \mathrm{ACTS}$ antenna which will be flown in 1992. The Japanese are also developing a Ka-band satellite having an antenna similar in size to the ACTS antenna. No $134 \mathrm{GHz}$ antennas have been developed. All of these antennas must also be supported with low loss feed systems $(0.4 \mathrm{~dB}$ for $\mathrm{Ka}$-band to $1.5 \mathrm{~dB}$ for $134 \mathrm{GHz}$ ). This area is at a technology readiness level of 1 .
Technology development for optical communications is required in the areas of laser transmitters, optical detectors, telescopes, and tracking/pointing systems. Most of these technology areas are at technology readiness levels of 2 to 3 with some specific components at higher maturity levels. The principle candidate laser sources are the solid state Nd:YAG laser and semiconductor diode laser. For ISL application the ND:YAG rod is pumped by means of GaAs semiconductor laser diode arrays. The output power capability of Nd:YAG depends on the operating mode (i.e., CW or pulsed). McDonnell Douglas, in efforts sponsored by DoD and NASA, has reported the generation of peak powers of $3750 \mathrm{~W}$ and average powers of up to $35 \mathrm{~W}$ from a diode-pumped Nd:YAG slab laser. In the cavity-dumped mode, a peak power of $50 \mathrm{~W}$ with an average power of $150 \mathrm{~mW}$ is the current status. Current commercial devices have been reported to have average power levels of approximately $4 \mathrm{~W}$ at $1.06 \mu \mathrm{m}(2 \mathrm{~W}$ at $0.53 \mu \mathrm{m})$ with a Nd:YAG laser with $10 \mathrm{~W}$ average power under development. For a homodyne or heterodyne system, the Nd:YAG laser offers narrow linewidth and good spectral purity over semiconductor lasers. Its disadvantage is that an external modulator is needed to modulate the laser which can introduce additional signal power loss and have a fairly large prime power requirement $(-100 \mathrm{~W})$. The lifetime of the laser is essentially established by the pumping diode array ( 40000 hours).

In the area of semiconductor lasers, commercial GaAs laser diodes suitable for direct detection systems are currently available with average output power in the 75-100 $\mathrm{mW}$ range. MIT Lincoln Laboratory (MIT-LL) recently reported the development of the first spacequalified coherent laser transmitter (a $30 \mathrm{~mW}$ GaAlAs semiconductor laser). TRW has recently developed a noncoherent diode array with $450 \mathrm{~mW}$ CW power and projects a $1 \mathrm{~W}$ coherent device in the near term.

Optical detectors commonly used in optical communication include PIN photodiodes and avalanche photodiodes (APD). Semiconductor photodetectors have the advantages of high quantum efficiency $(60-90 \%)$, high bandwidth (> $1 \mathrm{GHz}$ ), high reliability, and small size. PIN diodes, which have no internal gain, are applicable to heterodyne and homodyne systems. Current silicon PIN diodes have quantum efficiencies of $60-90 \%$ at $0.532 \mu \mathrm{m}$ and $0.85 \mu \mathrm{m}$ wavelengths and $40 \%$ at the Nd:YAG fundamental wavelength of $1.064 \mu \mathrm{m}$. An AIGaAs PIN device custom made by MIT- LL has an $85 \%$ quantum efficiency at $0.85 \mu \mathrm{m}$. For direct detection systems, thermal noise is overcome by using an APD with large internal gain. Current state-of-the-art reach-through 
Si APDs have gains of $100-300$, quantum efficiencies in the range $80-90 \%$ at $0.532 \mu \mathrm{m}$ and $0.85 \mu \mathrm{m} \mathrm{(40 \%} \mathrm{at}$ $1.064 \mu \mathrm{m})$, and excess noise factors (F) of 2.8-3.2 $(F=1$ is ideal). InGaAs APDs for detection at $1.064 \mu \mathrm{m}$ wavelength have gains up to 50 , quantum efficiency of $80-90 \%$, and excess noise factor of 5.5 . Typical bandwidths of APDs range from $100 \mathrm{MHz}$ to $4 \mathrm{GHz}$ at visible and near-infrared wavelengths. Overall, solid state photodetector technology is mature and space-qualified devices should exist by 1997.

Because of the high cost of low loss lens materials and weight penalty associated with refractive optics, reflective optics are the preferred choice for large telescope designs $(>10 \mathrm{~cm}$ ). Using metal foam core mirrors, the University of Arizona has built a $30 \mathrm{~cm}$ aperture Cassegrain telescope weighing only $4.5 \mathrm{~kg}$. Light weight optics is especially important for the optical Mars return link. Besides low weight and cost, large diameter optics must also have high surface quality, good thermal stabilization, and be protected from contamination (e.g., spacecraft exhaust).

Based on the link analysis described in section 4.4, the tracking/pointing subsystem must be capable of sub-microradian accuracy $(<0.1 \mu$-radian) for the $100 \mathrm{Mbps}$ optical link. Based on measured LANDSAT platform jitter, current achievable tracking error is approximately $0.5 \mu$-radian.

\subsection{Information Management Technology Assessment}

The Information Management (IM) technology areas identified in this study are data compression and data storage. Data compression techniques attempt to reduce or eliminate redundancy in the data to minimize the amount of information which needs to be transmitted. Data compression is needed primarily to reduce data transmission rates and limit requirements on data storage units. Data compression methods can be categorized as either reversible (i.e., lossless) compression techniques or lossy techniques. Reversible techniques provide the best quality but the least compression. Applications where data cannot be lost will require reversible compression. Lossy techniques can provide sufficient quality for certain applications with acceptable compression ratios. Although there are many data compression schemes not aimed specifically at image data such as the commonly used Lempel-Ziv algorithm, most data compression schemes are for image data compression $^{11}$ since that is the area where the potential for data rate reduction is greatest. For data compression, the parameter which describes the level of compression needed is the compression ratio. The technology needs identified range from 10:1 compression for lossy techniques and 2:1 compression for lossless techniques in Option-1 (technology readiness level of 4) to compression ratios of 50:1 for lossy techniques and 10:1 for lossless techniques in Option-4 (technology readiness level of 3). The choice of any data compression schemes will ultimately be application dependent.

Space-based data storage is required as an on-line buffer for bursty transmissions, for in situ archiving of data, and to prevent loss of data during periodic outages or unavailability of the communications links. The most critical criteria for data storage media other than volatility and stability are the read/write rates and the mass data storage capacity. The data storage requirements across the various options range from capacities on the order of 100's of Mbytes and read/write rates of 10's of Mbps in Option-1 to capacities of 10's of Tbytes and read/write rates of about 1 Gbps in Option-4, increasing by roughly one order of magnitude in each successive option. The technology readiness level in Option-1 and 2 is about level 4 because the capacity is not really difficult to achieve and the required read/write rates are not significantly beyond what is currently achievable. However, in Option-3 and 4, the technology readiness is judged to be no more than at level 2 due to the technology development required to meet the $\mathrm{read} / \mathrm{write}$ rate requirements, as well as the substantial increases in capacity.

\section{Development Schedule for the 4 Options}

Figure 6-1 provides a generic time line for use in laying out a technology and program development plan. It shows how base research and technology is drawn upon during pre-phase $A$ studies to help in formulating the conceptual designs for the program under development. By the end of the pre-phase $A$ study period, appropriate technologies have been identified for focused technology development efforts. Interaction and joint feedback occurs during the phase $A$ and $B$ study periods, as progress on development of focused technologies influences the phase $A$ and $B$ design parameters, and the phase $A$ and $B$ study results serve to further focus the technology development requirements. By the end of the phase B study period, technology development has progressed to readiness level 6 where system validation models have been tested in a relevant environment. As the program development enters phase $C / D$, focused technology development continues to support the current program needs as 
well as examining related technology requirements for future missions.

The time line shown in figure 6-1 is useful as a guide in generating technology and program development plans. Differing technology areas, however, may require different specific time lines to achieve equivalent advances in the state of technology readiness. For example, travelling wave tube amplifiers (TWTAs) and solid state power amplifiers (SSPAs) are entirely different technologies that perform the same operation; that is, final amplification of the signal prior to transmission over the link. A TWTA is based on electron beam technology, while an SSPA is the result of transistor theory. This technology difference results in greatly varying methods of designing an amplifier. The technology differences also effect the suitability of TWTAs and SSPAs for specific applications. Representative technology development schedules are shown in figures 6-2 and 6-3, for TWT and SSPA development, respectively.

Figure 6-2 shows the major activities required in the design through space qualification of a travelling wave tube. The initial TWT design is performed with the aid of specialized computer programs. Subsequent refinement of the RF circuit design is carried out with respect to bandwidth, efficiency, stability and distortion requirements. Refinement of the electron gun and the periodic permanent magnet structure to meet special requirements, such as dual-power mode operation; design of the multistage depressed collector, including the cooling system; and design of the overall TWTA package for the thermal and mechanical properties of the space environment, are all carried out in parallel with the RF circuit design process. "Cold-testing" is the process of optimizing the tube performance with respect to the critical frequency without the electron beam being present. Throughout the design activities, intermediate testing takes place along with fabrication and parts procurement. Upon completion of final testing, the experimental TWT undergoes space qualification procedures by operating the tube in a simulated space environment. The entire process, representing technology development from readiness level 3 through level 6 , requires approximately three (3) years, assuming sufficient funding is available throughout the period.

The development schedule for a representative SSPA is shown in figure 6-3. As with the TWTA, an SSPA development program begins with computer aided design to refine the device and circuit parameters to achieve gross specifications. Once the initial design is complete, the device technology is developed to match the design. This development includes substrate growth, masking, etching, substrate thinning, and metalization. This is typically an iterative process, as it is difficult to fabricate what has been theoretically designed. Problems can arise in achieving the doping profile; impurities may become present in the fabrication process and can prevent proper device operation. Part three of the device development process concerns combination of the individual stages into an overall amplifier, with emphasis given to bandwidth, losses and interstage matching. Power supply design is conducted in parallel with this effort. Finally, the devices and combiners are assembled into the full SSPA and tested in a relevant environment. The overall development program, representing technology development from readiness level 3 through level 6 , requires approximately four (4) years, again assuming sufficient funding is available.

\subsection{SEI Architecture Time Frames}

Technology development schedules are in a large way driven by the SEI program architecture within which the technology must fit. Program architecture alternatives are currently under study through various means both within and outside of NASA. The final program architecture will be the result of a synthesis of ideas coming from NASA, federally sponsored research, an AIAA study, and direct solicitation. One approach to architecture definition might involve selecting architectures which achieve various strategies. An example of this approach is shown in table 6-1, where the strategies involved are exploration emphasis, expanding human presence, aggressive Mars emphasis, modified reference (science emphasis), and energy enterprise. A full architecture definition is far more detailed than what is given in table 6-1, however the table does serve to point out major differences among the various example architecture approaches. An element not shown in table 6-1 but applicable to all of the architectures is the robotic phase with missions to the Moon and Mars beginning with the Mars Observer mission in 1992 and the Lunar Observer mission in 1996.

Since the goals of the various architectures differ significantly, the time lines associated with each architecture vary. These time lines and the associated architecture assumptions, in turn, impact the technology development time lines for those technologies needed to support the various missions. In particular, this options study has addressed those technologies associated with various telecommunications requirements of the missions. 
Each of the four telecommunications options presented in this study could be applied to any of the architectures discussed, but with attendant constraints, such as bit rate limitations.

\subsection{Technology Development Schedules}

Tables 5-3 to 5-6 discussed in section 5 contain technology readiness levels for each of the technology development requirements within the four options examined in this study. These readiness levels can be used with figure 6-1 to develop a program plan for technology development which can fit within the constraints of the SEl architecture that will be chosen. In the previous section, five example architectures were briefly discussed. The specific architecture for the SEI program will be selected on the basis of a set of "goodness criteria", resulting from both technical and political concerns. This final architecture may not be known for perhaps several years, which adds a degree of uncertainty to the task of determining a technology development program plan. Differing milestones across the various architectures require different phasing, emphasis and prioritization within the technology development program, particularly in the early, uncertain years of the program. In these years, emphasis must therefore be placed on broader reaching technologies which may be applicable to a wide range of architectures. The remainder of this section will introduce, in a general way, technology development schedules across the four options.

This study has addressed telecommunications requirements for the lunar/Mars evolutionary phase, involving manned flight support for the Moon and Mars. The robotics phase will obviously have telecommunications requirements as well, however, the return link data rate requirements are envisioned to be somewhat lower for the robotics phase than the manned phase and therefore the requirements on the telecommunications systems will be less stringent. Therefore, the schedules to be addressed here will be based upon time lines for manned flight activities, as exemplified by the dates shown in table 6-1. The suitability of each of the options to support the data throughput requirements is addressed in section 3 .

Option-1 involves S-band links for the lunar missions and $X$-band links for Mars. As technology for both $S$ and $X$-band is reasonably mature, the technology development needed to support the mission scenarios is primarily that of tailoring existing designs to specific applications. Accordingly, technology readiness levels for Option-1 are at, or near, level 4. Figure 6-1 shows that approximately two years of focused technology development would be needed to advance the required technologies to a system validation stage (level 6) for integration into a flight development program. Assuming six years are required for the flight program development, to meet the earliest manned flight telecommunications requirements for the Moon and Mars as shown in table 6-1, technology development for Option-1 should begin in 1992 and 1996, respectively, for the lunar and Mars missions.

$X$-band lunar links are assumed for Option-2. The technology development schedule would be similar to that discussed for Option-1, with a 1992 start-up. For the Mars missions, Ka-band technology has been assumed. Readiness levels, shown in table 5-4, range from 2 to 4 . Figure 6-1 indicates that six years of focused development are needed on average to develop a given technology element from level 3 to level 6 . (The example schedules shown in figures 6-2 and 6-3 indicate that somewhat less time may be required for some technology elements.) Development from level 2 could require one to four additional years. This would imply that to meet the earliest Mars mission scenarios, focused Ka-band technology development should begin almost immediately. These earliest Mars scenarios, as exemplified by the Aggressive Mars and Exploration Emphasis architectures, however, might be expected to have lower return link data requirements than would be required for later outpost support. The lower data requirements would tend to relax the technology development needs.

Option-3 assumes Ka-band links for both lunar and Mars missions. Lunar and Mars mission technology readiness levels range from 2 to 4 , with generally more ambitious requirements assumed for the more challenging Mars links. Space-to-Earth data rates achievable with Option-3 are $325 \mathrm{Mbps}$ and $10 \mathrm{Mbps}$ for the Moon and Mars, respectively. These data requirements would be appropriate once outposts have been established. The earliest lunar outpost among the five example architectures would happen in 2002, while the first Mars outpost is planned for 2012. To meet these time frames, lunar technology requirements which are at level 2 (e.g., MMIC devices and multibeam phased array antennas) should be started in the very near future. Mars-specific technology requirements would need to be initiated in the 1995-96 time frame.

Option-4 again assumes Ka-band technology for both Moon and Mars links. An optional space-to-Earth link using optical technology is also examined for the Mars return link. Return data rates are similar to those assumed for Option-3 (350 Mbps for the lunar 
return link and 10 Mbps for the Mars RF return link). An optical $100 \mathrm{Mbps}$ return link is also examined. Table 5-6 shows that readiness levels range from 1 to 4 for both lunar and Mars technologies with Mars requirements again more demanding. The least mature technologies are associated with the Earth relay satellites (GRS) (e.g., low-loss feeds, low-noise receivers, very large reflectors). Base technology work is needed to study the feasibility of the GRS antenna systems. This work should begin in the 199293 time frame to examine the viability of using a GRS for the Mars links. Similar studies should be undertaken in the same time frame to determine the feasibility of large space-born telescopes $(10 \mathrm{~m})$ and high power lasers for an optical return link from Mars to an optical GRS. The remaining Mars-specific technology elements should begin focused development in the 1995-96 time frame. To meet the earliest lunar outpost requirements, technology development for level 2 elements should begin in the very near future.

Table 6-2 summarizes the technology start-up time frame requirements for the four options as described above. These start times are based on the mission requirements associated with the five example architectures discussed in section 6.1. The table serves to highlight the need for near term initiation of technology development activities in order to satisfy the early lunar mission requirements. Of course, the selection of exploration mission architectures and time lines that are different from the examples used here, would change the technology development schedules.

\section{Conclusions}

Examination and analysis of the four alternative architectures has identified the critical technology elements that require significant development in order to maintain the proposed mission schedules and to provide the necessary levels of reliability and maintainability for long duration manned spaceflight. This study has identified $\mathrm{Ka}$-band communications technology to meet the near term mission requirements. $\mathrm{X}$-band communications technology was shown to have some merit and would be suitable as a back-up during emergencies. Providing for growth capability of the data transmission rates requires continued development of higher RF frequencies $(60 \mathrm{GHz}, 94 \mathrm{GHz}, 134 \mathrm{GHz}$ ) and optical communications technologies.

Critical areas that require development for Ka-band communications technology include: advanced multibeam antenna concepts utilizing MMIC phased arrays; high-power TWTAs; high efficiency SSPAS, baseband processing and switching; power and bandwidth efficient modulation and coding; low noise receivers; and, low loss demodulators. The major areas for optical technology include development of diode-pumped $\mathrm{Nd}: \mathrm{YAG}$ and semiconductor laser transmitters that have high power, efficiency and reliability, and development of large diameter, lightweight, diffraction-limited optics. In support of the Mars return link, both RF and optical systems require development of pointing and tracking systems and platform disturbance rejection methods to minimize pointing and tracking errors. Critical technologies for Information Management are data compression and data storage to reduce real-time data rates and to lessen the impact of the requirements on the system design. It is concluded that funding and near-term initiation of technology development activities is necessary to satisfy candidate mission time frames for the Space Exploration Initiative.

\section{B References}

[1] NASA Report prepared for the National Space Council, "Report of the 90-Day Study on Human Exploration of the Moon and Mars", November 1989.

[2] Bruno, R., Jacobsen, A., Messing, M., Shapiro, P., "Definition and Evaluation of Alternative Communication Systems Architectures for Lunar Missions", prepared by STel and CSC under contract with NASA Goddard Space Flight Center, submitted to MASE 1989 Final Report Volume 6, September 1989.

[3] Hall, J. R., Hastrup, R., Sue, M., Alwar, V., Smith, J., "Telecommunication, Navigation and Information Management Design for Mars Exploration Based on the 1989 Case Studies", Jet Propulsion Lab, submitted to the MASE 1989 Final Report - Volume 6, September 1989.

[4] Miller, E. F., Ponchak, D. S., Zuzek, J. E., Long, K. J., "Assessment of Technology Alternatives for Telecommunications, Navigation, and Information Management for Lunar and Planetary Exploration Based on 1989 Case Studies", NASA Lewis Research Center, submitted to MASE 1989 Final Report-Volume 6, September 1989.

[5] International Telecommunications Union, "Radio Regulations", Edition of 1982, Geneva, Switzerland, 1982

[6] Farquhar, Robert W., "The Utilization of Halo Orbits In Advanced Lunar Operations", NASA 
Technical Note TN D-6365, Goddard Space Flight Center, July 1971

[7] Zeilik, M., and Smith, E.v.P., "Introductory Astronomy \& Astrophysics - Second Edition", 1987, CBS College Publishing, New York, NY, 10017

[8] CCIR Report 719-2 \& Revisions, "Attenuation By Atmospheric Gases", CCIR, Dubrovnik, Yugoslavia, 1986

[9] Crane, Robert K., "Prediction of Attenuation by Rain", IEEE Transactions on Communications, Vol. COM-28, No. 9, September 1980, pp. 1717 1733

[10] Astrophysical Information Systems Workshop, May 23-25, 1990, Annapolis, MD, sponsored by NASA/Astrotech 21

[11] Ponchak, D.S., Zuzek, J.E., Whyte, W.A., Jr., Sohn, P.Y., and Spence, R.L., "Deep Space and Space-to-Earth Link Budgets", Appendices to "A Technology Assessment of Alternative Communications Systems For The Space Exploration Initiative", NASA Lewis Research Center - Internal Report, July, 1990

[12] Alexovich, R., Hartz, W., and Neustadter, M., "Data Compression Techniques Applied to High Resolution High Frame Rate Video Technology", NASA Contractor Report 4263 by ANALEX Corp. under Contract \#NAS3-24564, December, 1989 


\begin{tabular}{|c|c|c|c|c|}
\hline & 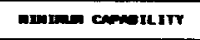 & 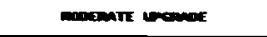 & wen & Fulp Boveros \\
\hline una serrear & $\begin{array}{l}\text { mear-side onily } \\
\text { surface/osh }\end{array}$ & $\begin{array}{l}\text { Mear-side only } \\
\text { Surfaco/0sin }\end{array}$ & 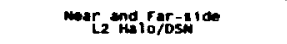 & wor and far-sides \\
\hline Frequency send & S- Bando & $x$ - & Na-Bano & So- \\
\hline Wol tak ostz aete. & $\cdots$ & $\cdots$ & $\cdots$ & --- \\
\hline meturn Date Rate" & 140 & 140 mos & 325 unp: & 350 thes \\
\hline Aalay satellite & mone & mone & $1-12$ LAS & L1,L2 LAS, processing \\
\hline $\bmod 1$ at $10 \cos / \operatorname{cod} 1 \mathrm{ng} \theta$ & CPSK / mone & $\cos x / \omega \operatorname{con} v$ & Cosk / Rs.conv & opsk / Rs.conv \\
\hline Motwork ops & Earkh-based & Earth-based & Cestbed/Earth overrido & fully unat tenderd \\
\hline Mavigation & Earth-based & Earth-basod/landing Gescoms & IN SITU/Lenaing boscons & In SI Tu/maviet \\
\hline mos supromt & 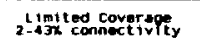 & $\begin{array}{l}\text { Increased Coverape } \\
\text { oflioox connoctivfy }\end{array}$ & cont invoow conerares. & $\begin{array}{l}\text { Moar } 100 x \text { coverage } \\
\text { cont inuow connect. }\end{array}$ \\
\hline Frequency eand & $x-8+0$ & X-BND/RA-BNO & U-ANos & Ka-Bano/optical \\
\hline upl Ink date Hate & $\cdots$ & $\cdots$ & $\ldots$ & $\cdots-$ \\
\hline pecurn pate hate & 250 kops/channel & 1 enps/channel & 10 Mpas/channel & $10 \mathrm{mops} / 100 \mathrm{mas}$ \\
\hline Relay satellite & mone & 1 ws, bentpipe & 2 mas i procensing & optical comm package \\
\hline nodilation/cooling & $\cos x / \operatorname{Rs}+\operatorname{con} y$ & Qpsk , ps + conv & conerent - FSK/nS-Conv & Coherent $16-F$ SK/RS * Cons \\
\hline matwork ops & Earth-dased & some unat tenderd func. & testbed/undrs overridio & fully unattended \\
\hline Maviastion & Earth-based & Earth-based/Lending Bascons & IM Situ/Landing Bascoms & IN Situ/MaVne.t \\
\hline EмaTh serent & Uses Existing DSM & Uses present OSN uporace & Recwires proposed OSN Updrade & men syrtem with cas \\
\hline Doep sasce witmork & I S- SAAD $26 \mathrm{n}$ SUANEI & 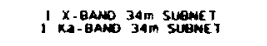 & 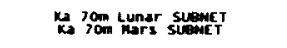 & $\begin{array}{l}\text { Argess-Typo } \\
\text { facility }\end{array}$ \\
\hline Belay sotelitite & $\operatorname{mon}$ & mone & None & 2 Cen aelay sat \\
\hline onta contession & 211 & $5: 1$ & 311 & 1011 \\
\hline Datin sremace & 10012 moytes & 1 coyte & 1 Tbyte & $10 \times$, Toycos \\
\hline mative cost & 1 & 3 & 10 & 20 \\
\hline
\end{tabular}
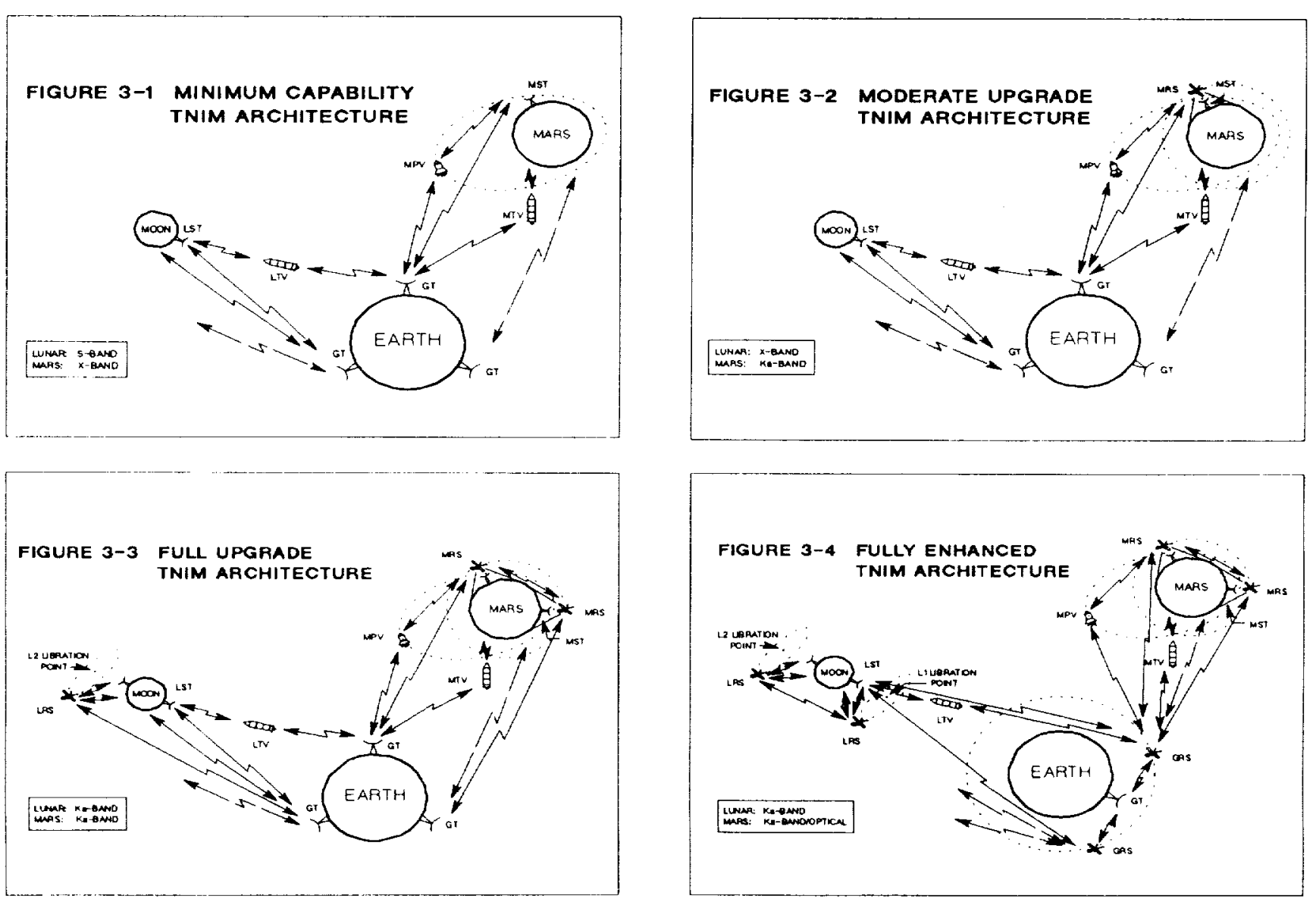
Floure 4-1 Cumulative Datribution of Earth-Mars Datances (2010 to 2013)

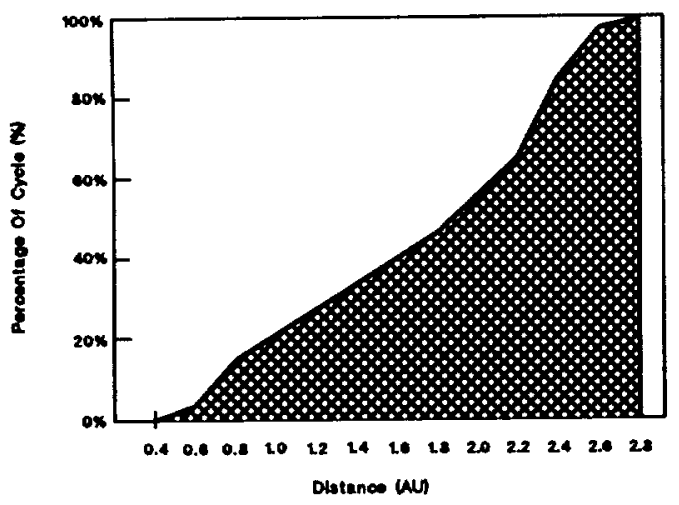

Flgure 4-3 Moon and Mars Sky Track - Canberra, Australla

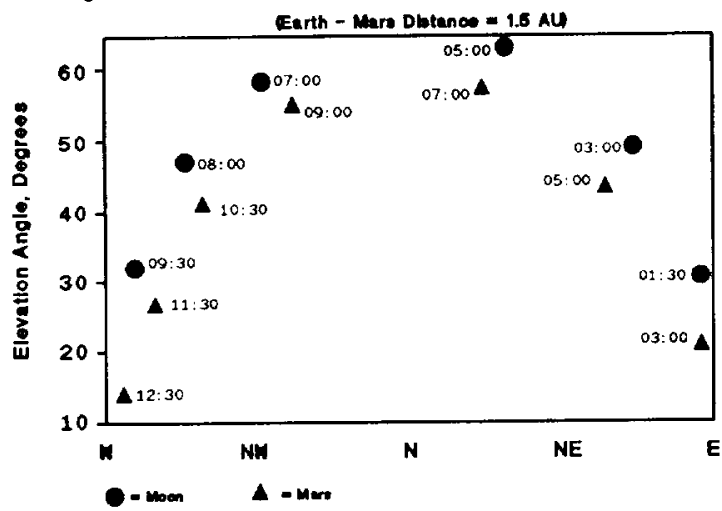

Figure 4-2 Moon and Mars Sky Track - Canberra, Australia Earth - Mars Distance $=0.6 \mathrm{AU}$

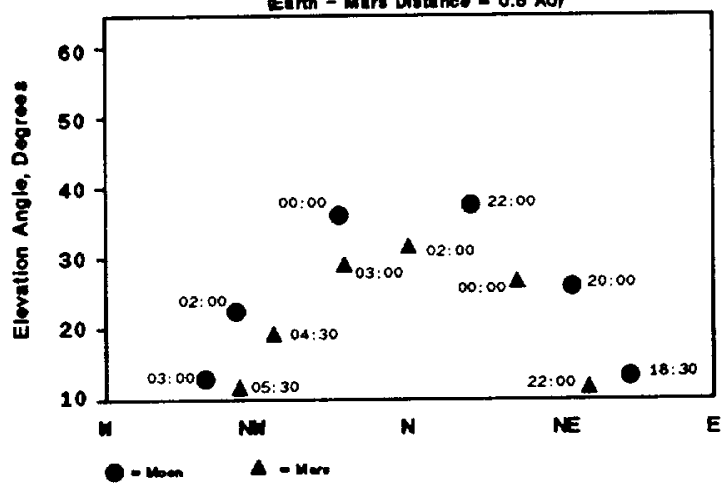

Floure 4-4 Moon and Mars Sky Track - Canberra, Australia Euth - Mars Distence -2.5 AL

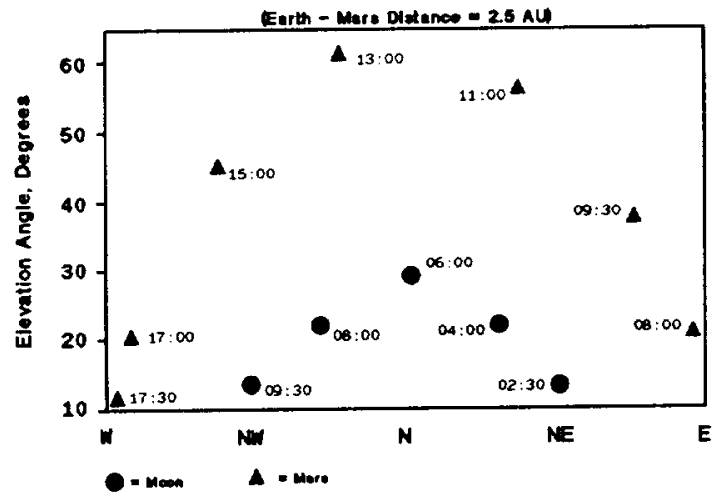

TABLE 4-1

LUNAR LINK ANALYSIS SUMMARY

\begin{tabular}{|c|c|c|c|c|c|c|c|}
\hline OPIION & DATA IINKK & FAEQUEACYCY & $\begin{array}{c}\text { TRANSHIT } \\
\text { POWER } \\
\text { (M) }\end{array}$ & 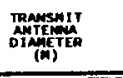 & 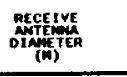 & 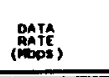 & comments \\
\hline 1 & LST TO GT & 2.25 & 48.0 & 5.0 & 26.0 & 140.0 & ou timiteo \\
\hline 1 & ROVER TO $G \mathrm{~T}$ & 2.25 & 170.0 & 1.0 & 26.0 & 20.0 & \\
\hline 1 & SCIEMCE TO GT & 2.25 & 47.0 & 0.3 & 26.0 & 0.5 & \\
\hline 2 & LST TO ET & 8.45 & 29.0 & 1.4 & 34.0 & 140.0 & antiteo \\
\hline 2 & ROVER TO CT & 8.45 & 2.9 & 1.0 & 34.0 & 20.0 & \\
\hline 2 & Sclawer to et & 8.45 & 1.0 & 0.3 & 34.0 & 0.5 & \\
\hline 3 & LST To $G T$ & 32.05 & 55.0 & 0.35 & 70.0 & 200.0 & \\
\hline $\mathbf{3}$ & DOVER to $\mathrm{GT}$ & 32.05 & 13.0 & 0.35 & 70.0 & 20.0 & \\
\hline 3 & SCIEMCE to CT & 32.05 & 4.0 & 0.10 & 70.0 & 0.5 & \\
\hline $\mathbf{3}$ & LST (FAR) TO 12 LAS & 32.05 & 5.6 & 1.0 & 2.0 & 100.0 & \\
\hline 3 & LST (FAR) TO L2 LAS & 8.45 & 60.0 & 3.0 & 2.0 & 100.0 & al tepanate faca. \\
\hline 3 & L2 LRS TO GT & 32.05 & 3.0 & 2.0 & 10.0 & 125.0 & \\
\hline 3 & L2 LAS TO 61 & 32.05 & 12.5 & 2.0 & 34.0 & 125.0 & \\
\hline 3 & L2 LRS TO EI & 0.45 & 9.0 & 2.0 & 34.0 & 125.0 & ALTERMATE I FEQ. \\
\hline 3 & LST (FAR) TO L2 LAS & 32.05 & 36.0 & 1.0 & 2.0 & 1000.0 & SCIEMCE INSTR. \\
\hline 3 & 12 LRS TO GT & 32.05 & 23.5 & 2.0 & 70.0 & 1000.0 & SCIEMCE INSTR. \\
\hline 4 & 12 LAS TO LI LAS & 32,05 & 3.3 & 2.0 & 3.0 & 125.0 & \\
\hline 4 & WL LAS TO LST (MENA) & 32.05 & 0.0 & 2.0 & 2.0 & 150.0 & \\
\hline 4 & LST (MEena) To cas & 32.05 & 42.0 & 2.0 & 5.0 & 350.0 & \\
\hline 4 & GeS TO GT & 20.45 & 1.1 & 1.0 & 20.0 & 350.0 & wite smos \\
\hline 1 & CRS TO GT & 20.45 & 1.6 & 0.5 & 34.0 & 350.0 & oss \\
\hline 4 & L2 LAS TO 11 LRS & 32.05 & 26.5 & 2.0 & 2.0 & 1000.0 & Scremce IMstr. \\
\hline 4 & LST (MEAP) TO CPS & 32.05 & 52.0 & 2.0 & 5.0 & 1000.0 & SCIEMCE INSTR. \\
\hline 4 & cos to $6 \mathrm{~T}$ & 20.45 & 3.0 & 1.0 & 20.0 & 1000.0 & wite savos \\
\hline
\end{tabular}


TABLE 4-2

MARS LINK ANALYSIS SUMMARY

\begin{tabular}{|c|c|c|c|c|c|c|c|}
\hline opriom & DATA LINK & 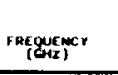 & 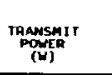 & 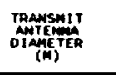 & 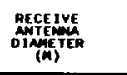 & 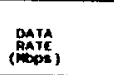 & comments \\
\hline 1 & mov ro ct & 0.45 & 00.0 & 5.0 & 34.0 & 0.25 & \\
\hline 1 & NSI TO SI & a.45 & 125.0 & 4.0 & 34.0 & 0.25 & \\
\hline 1 & Rovef to $\mathrm{ct}$ & 6.45 & 200.0 & 2.0 & 34.0 & 0.10 & \\
\hline 1 & SCICMCE TO ET & e.45 & 125.0 & 2.5 & 34.0 & 0.10 & \\
\hline 2 & ans, wV to $6 \mathrm{~T}$ & 32.05 & 100.0 & 5.0 & 34.0 & 1.0 & \\
\hline 2 & mas to & 32.05 & 200.0 & 7.8 & 34.0 & 1.0 & \\
\hline 2 & was $10 \mathrm{GT}$ & B.45 & 200.0 & 3.1 & 34.0 & 1.0 & alteraute treq. \\
\hline 2 & As r to WHs & 32.05 & 7.0 & 0.3 & 1.0 & 20.0 & \\
\hline 2 & movit to was & 32.05 & 7.9 & 0.2 & 1.0 & 10.0 & \\
\hline 2 & SCIENCE TO mas & 32.05 & 1.6 & 0.1 & 1.0 & 0.5 & \\
\hline 3 & WAS TO GT & 32.05 & 180.0 & 9.0 & 20.0 & 10.0 & \\
\hline 3 & mas To $\mathrm{ct}$ & 0.45 & 135.0 & 9.0 & 20.0 & 10.0 & AL TEAMMTE fREO. \\
\hline 3 & movet & 32.05 & 182.0 & 5.0 & 70.0 & 3.ะ & \\
\hline 3 & WS t to mas & 32.05 & 5.7 & 0.5 & 1.0 & 50.0 & \\
\hline 3 & ROVER TO mas & 32.05 & 6.6 & 0.3 & 1.0 & 20.0 & \\
\hline 3 & Scirmce to mas & 32.05 & 1,4 & 0.1 & 1.0 & 0.5 & \\
\hline 3 & mas: 1 to Masz & 32.05 & 2.3 & 1.0 & 1.0 & 40.0 & \\
\hline 4 & was, wy to CAS & 32.05 & 110.0 & 5.0 & 36.0 & 10.0 & \\
\hline - & mos TO GRS & 32.05 & 110.0 & 10.0 & 20.0 & 10.0 & \\
\hline 4 & MRS, MPY TO CRS & 60.00 & 115.0 & 5.0 & 27.0 & 10.0 & \\
\hline 4 & mas to CAS & 60.00 & 115.0 & 10.0 & 15.0 & 10.0 & \\
\hline+ & NAS, wPV 10 cRs & $94 . \infty$ & 115.0 & 5.0 & 22.0 & 10.0 & \\
\hline 4 & mRs 10 CAS & 94.00 & 115.0 & 10.0 & 12.0 & 10.0 & \\
\hline 4 & mas, mov io cas & 134.00 & 110.0 & 5.0 & 20.0 & 10.0 & \\
\hline 4 & Was to GRS & 134.00 & 110.0 & 10.0 & 11.0 & 10.0 & \\
\hline
\end{tabular}

\section{TABLE 5-1 NASA TECHNOLOGY READINESS/MATURATION LEVELS}

\section{TECHNOLOGY DEVELOPMENT}

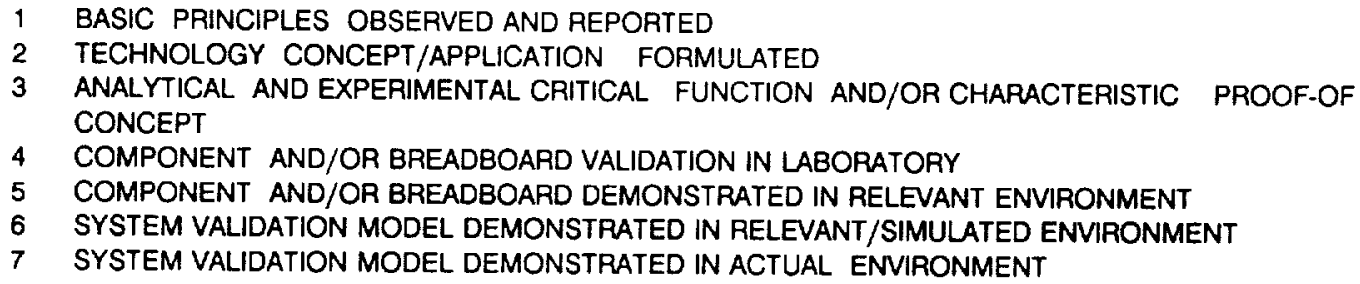

\section{ADVANCED DEVELOPMENT}

8 TECHNOLOGY APPLIED TO CONSTRUCTION OF COMPONENT AND/OR BREADBOARD OF EXPECTED FLIGHT HARDWARE CONFIGURATION

9 CAPABILITY OF FULL SCALE SUBSYSTEM PROTOTYPE DEMONSTRATED IN GROUND TESTS

10 CAPABILITY OF FULL SCALE SUBSYSTEM PROTOTYPE DEMONSTRATED IN ACTUAL ENVIRONMENT

\section{FUGHT HARDWARE DEVELOPMENT}

11 FULL SCALE SYSTEM PROTOTYPE

12 CAPABILITY DEMONSTRATED IN FLIGHT TEST OF FLIGHT HARDWARE

13 CAPABILITY DEMONSTRATED BY OPERATIONAL FLIGHT EXPERIENCE 
TABLE 5-2

RF TECHNOLOGY ASSESSMENT COMPARISON

\begin{tabular}{|c|c|c|c|c|}
\hline & OPTIOM-1 HIMIMUM CAPABILLTT & OPTION-2 MOOERATE CAPABILITY & OPIJOM-3 FULL UPCANDE & OPTION-A fultr Entranced \\
\hline \multirow{12}{*}{$\begin{array}{l}\mathbf{L} \\
\mathbf{y} \\
\mathbf{A} \\
\mathbf{A}\end{array}$} & POW/OW EFF MODULATION & POW/BW EIF MOOUATIION & MECH STEERABLE PEFLECTOR & MECM STEERAOLE REFLECTOA \\
\hline & S-Bano trita & & ELEC SWITCHED F 1 XED BEANS & ELEC SWI ITHEO F IXED BEANS \\
\hline & & & ELTC steERED phased apeaA & ELEC STEEAEO PHAaseo ahaAY \\
\hline & & & 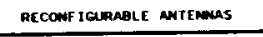 & 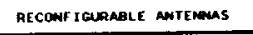 \\
\hline & & & Ka-BAND TWTA & Ka-BANO S/C REFLECTOA \\
\hline & & & $K_{A} \cdot$ Band SSPA & Ka-gano TMIA \\
\hline & & & MIC DEVICES & $\mathrm{Ka}=\operatorname{\theta ang} \operatorname{ssp} x$ \\
\hline & & & Ka-BANO CARTH STARION & mic DEVICES \\
\hline & & & & LON LOSS FEED SYSTEM \\
\hline & & & & BASEBANO PROCCESSINC: \\
\hline & & & & LOW moISE Ka RTCEIVERS \\
\hline & & & & REED SOLOMON/CONN DECOOER \\
\hline \multirow{14}{*}{$\stackrel{\hat{A}}{\mathrm{~A}}$} & X-QNAOS S/C REFLECTOR & Ka-BANOS/C REFLECTOA & Ka-QNONOS/C REFLECTIOR & Ka-BNo S/C REFLECTOA \\
\hline & $x$ - Banotha & MECH STIERABLE REFLICTOA & MECH STEERABLE REFLECTOA & mECh STEEarable perLfector \\
\hline & & ELCC SWITCHED FIXED EEAMS & ELEC SWI TCHED FIXED DEAMS & ELEC SWITCHED F IXED BEANS \\
\hline & & S/C ANTENA POINT ING & LLEC STEEAED PHASED nRPAY & ELEC STEEAED PHASED ARRAY \\
\hline & & Ka-BANOO TRTA & S/C ANTEMAMA POINTING & S/C ANIEMANA POINTING \\
\hline & & Ka-Bamo Sspa & xa-Bano this & $\mathrm{K} 2,60,94,134 \mathrm{cHz}$ WNIA \\
\hline & & LON LASS DEMOCULATOR & Ka-BAND SSPA & Ka-BANO SSPA \\
\hline & & KA-BAND GARTH STATION & mic devices & Milc devices \\
\hline & & & LOU LOSS DEMOULLATOR & LON LOSS DEMOOULATOR \\
\hline & & & PONER EFFICIENT MOCHLATION & PONER EFTICIENT MOOULATION \\
\hline & & & DASEBANo PPOCESSING & BASEBANO PROCESSIIMG \\
\hline & & & Ka-BAMO EARTH STATIOON & LOW MOISE ARCrIVERS \\
\hline & & & & LOW LOSS FEEO STSTEM \\
\hline & & & & REEO SOL DMOM/CONY DECOOCR \\
\hline \multirow[t]{2}{*}{ I } & OATA CONPRESSTOM & DATA COMPHESSION & DATA COMPRESSION & DATA COMPRESSIOE \\
\hline & DATA STORAGE & OATA STORAGE & DATA STORAGE & DATA STOHAGE \\
\hline
\end{tabular}

TABLE 5-3

RF TECHNOLOGY ASSESSMENT FOR OPTION-1 MINIMUM CAPABILITY

\begin{tabular}{|c|c|c|c|c|}
\hline & TECHELLOGY & TECHWOLOGY REOU IREMENT & TECHWOL OGY APPL ICATIONS & TAL \\
\hline \multirow{2}{*}{$\begin{array}{l}\text { L } \\
\mathbf{A} \\
\mathbf{A} \\
\mathbf{A}\end{array}$} & POWER/EN EFFICIEMT MOOULATIOM & $2 \mathrm{~b} / \mathrm{s} / \mathrm{Hz}$ & LST RE TURN DATA LIMK & 4 \\
\hline & S-BANO NTA & $2150 \mathrm{~W}$, HIG EFF & ROVER RE TUPA DATA LIMK & 4 \\
\hline \multirow{2}{*}{$\stackrel{\hat{A}}{\hat{\mathrm{R}}}$} & $X$-gan S/C RETLEC JOA & $5 \mathrm{~m}, 55 x$ & Mor AE TUEN DATA LINK & $3-4$ \\
\hline & $x$-Bano TwTa & BO.200 V, HICH EFF & ALL RETURM DATA LIINS & 4 \\
\hline \multirow{2}{*}{ ns } & DATA COMPRESSION & $10: 1$ (LOSSY) / $2: 1$ (LOSSLESS) & YIDEO NDO DATA SIOMALS & 4 \\
\hline & DATA STORAGE & 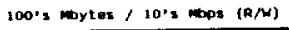 & All TNIM mooks & 4 \\
\hline
\end{tabular}

TABLE 5-4

RF TECHNOLOGY ASSESSMENT FOR OPTION-2 MODERATE CAPABILITY

\begin{tabular}{|c|c|c|c|c|}
\hline & TECINOLOGY & TECHWOLOGY REQUIREMEKT T & TECHMOLOCY APPL ICATIOANS & TRL \\
\hline \multirow{2}{*}{$\begin{array}{l}\mathbf{L} \\
\mathbf{u} \\
\hat{A} \\
\hat{R}\end{array}$} & POAER/EW EFFICIENT MOOULATION & $2 \mathrm{D} / \mathrm{s} / \mathrm{Mz}$ & LST PETUPM OATR LIAKK & - \\
\hline & & & & \\
\hline \multirow{8}{*}{$\stackrel{\hat{A}}{\hat{\mathrm{Q}}}$} & Ka-Bana $S / C$ PEFLECTRA & $5 \mathrm{~m}, 55 x$ 50 $0 \mathrm{~m}, 45 x$ & WOV NO MRS RETUAN DATA LIMK & 2 \\
\hline & MECHANICALLIY STEERABLE REFLECTOO & $5-8 \mathrm{~m}, 360^{\circ}$ & 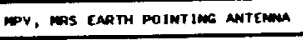 & 2 \\
\hline & ELEC SUITCHEO FIXED BEAM AMTCMNA & 10-8cams & mis MaAs ANTERMA & 4 \\
\hline & S/C ANTERNM POINTING & -0.01 deo & 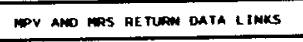 & 2 \\
\hline & KA-BAND TWTA & ग200 W. HIGH ETF & UPV ANO MAS AE TUREN DATA MINKS & 2 \\
\hline & Ka-BAND SSPA & $1-10=$ & SC IEMCE INSTRUWENTS NOO ROVERS & 2 \\
\hline & LOW LOSS DEMOOULATOR & $1.5 \mathrm{dg}$ & ALL DSN SITES & 4 \\
\hline & KA-BNNO EAATM STATHON & $34 \mathrm{I}$ ANTENAA, LON MOISE RECEIVER & osm uparnor & 3.4 \\
\hline \multirow{2}{*}{ I } & DATA COMPRESSTION & $15: 1$ (Lossy) / 5:1 (LossLess) & VIDCo ano oAtA stomals & 3 \\
\hline & DATA STORAGE & 1 coyte 1 100's mon $(R / W)$ & ALL Twin moOES & 4 \\
\hline
\end{tabular}


FULL UPGRADE

\begin{tabular}{|c|c|c|c|c|}
\hline & TECrmology & TECMOLOCY REQUIAEMEMT & 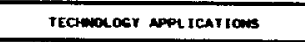 & ThL \\
\hline \multirow{8}{*}{$\begin{array}{l}\hat{L} \\
\hat{\mathbf{A}}\end{array}$} & MECHEMICALLY STEERABLE REFLECTOR & $2 \mathrm{~m}, 90$ & LRS FAR-SIDE COVERAGE & 3 \\
\hline & ELEC SWITCHED FIXED BEAM ANIEMMA & 10- BEAMS & LAS INA-S IOE COVERAace & 4 \\
\hline & 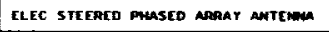 & 10-BENGS & LAS TAG-SIOE COVERACE & $2-3$ \\
\hline & 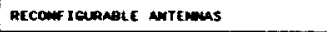 & panseo apray fEed & maINTAIM LAS DEAM SIZE & $2-3$ \\
\hline & Ka-men NTIA & 10-55 W, HTEH EFF & 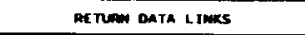 & 3 \\
\hline & KA-QNOS SSPA & $3-10 x$ & SCIEMCE INS TRUMENATS & 2 \\
\hline & mic devices & LOKR MOISE / HIGER POWER & mased amRars NoO SSPA & 2-3 \\
\hline & Ka-GNO ENATH STATION & $70 \mathrm{~m}$ ewtenand, Lau molse geceiver & DSW upcriat & $2-3$ \\
\hline \multirow{12}{*}{ 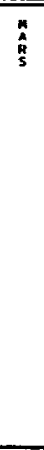 } & KA-BAND S/C REFLECTOA & $5 \mathrm{~m}, 55 x$ to $9 m, 45 x$ & 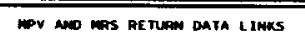 & 2 \\
\hline & MECWUNICALLY STEERABLE REFLECTOR & $5-9 \mathrm{~m}, 3600$ & mor, was CARTH POINTING MUTEMm & 2 \\
\hline & CLEC SWITCMED HIKED BEAM ANIEMMA & 10-ernus & mas MAPS Mitememe & 4 \\
\hline & Clic steereo prused naray miteman & 10. Benams & MAS MAS NHTEMUM & $2-3$ \\
\hline & S/C NETENOA POINTIMG & $-0.01 \mathrm{deg}$ & 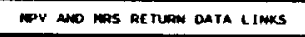 & 2 \\
\hline & Ka-gmo Tw/A & $180 \mathrm{~W}$, HIEH ECH & Dor ANO weS RETURM OATA LIMKS & 2 \\
\hline & Ka-BANO SSPA & $1-10 \mathrm{~W}$ & SCIEMCE INS TRUMLNIS NO ROVERS & 2 \\
\hline & mic devices & LOMER MOISE / MIOHER POMER & prusced apgatiss na SSPA & $2-3$ \\
\hline & LON LOSS DEMOOULATER & $1.5 \mathrm{dg}$ & ALL OSN SIITS & 4 \\
\hline & DOMER EFFICIENT MODULATIOM & 9-Fsk & 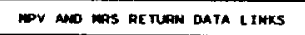 & 2 \\
\hline & BASEOANO PROCESSIMC NMO SWITCHIMC & ACIS IOUIVALENT & mas ano mo & 4 \\
\hline & Ka-BANO EARTH STATION & 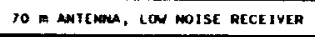 & DSN UPGRADE & 2.3 \\
\hline \multirow{2}{*}{ I } & DATA COMPRESS $10 \mathrm{~N}$ & $20: 1$ (Lossr) $/ 511$ (Lossicss) & VIOEO MNO DATA SICMALS & 3 \\
\hline & CATA STORAGE & I Thyte $/ 1 \cos s(\mathrm{~A} / \mathrm{M})$ & ALL TNIA MOOES & 2 \\
\hline
\end{tabular}

TABLE 5-6

RF TECHNOLOGY ASSESSMENT FOR OPTION-4

FULLY ENHANCED

\begin{tabular}{|c|c|c|c|c|}
\hline & Tecrmolocy & TECAMOLO DGY REQNIAEMEMT & TECHADOOGY NPPL ICATIONS & TAL \\
\hline \multirow{12}{*}{$\begin{array}{l}\mathbf{L} \\
\hat{\mathbf{y}} \\
\hat{\mathbf{a}}\end{array}$} & MECHENICALLY STEERNALE REFLECTDA & $2 m, 90$ & MEAR-S IDE/FAR-SIDE COYERACE & 3 \\
\hline & 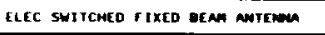 & 20-06ans & MENR-S IDE/FAR-SIDE COVERAGE & 4 \\
\hline & 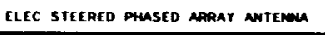 & 20-8r ans & MEMR-S JDE/FAR-SIDE COVEFAGE & 2 \\
\hline & AECOMF ICURABle MUTEMALS & praseo naray feed & MaIMTAIM LAS BLAM SIZE & 2-3 \\
\hline & Ka-BNe S/C REFICTTOR & $5 m, 55 x$ & LST TO CeS DarA IINKK & 2 \\
\hline & Ka-BNAO TWTA & $10-55 \mathrm{~W}$, Н1С GFF & LST to cess DarA I twaks & 3 \\
\hline & Ka-QNNO SSPA & $3-10 *$ & ALL IMTRE LUmaR OATA IINKS & 2 \\
\hline & mic ofvices & LONER MOISE / HIGHER POMER & prased aprars amo SSPa & $2-3$ \\
\hline & IOU LOSS FEco SYSIEM & 0.40 & CAS RECEIVER & 1 \\
\hline & Dascamo processsinc amo SWITCHINC & ACTS EOUIVALENT & 11 LRS, 12 LRS, CRS & 4 \\
\hline & LOW NOISE KA-BANO RECEIVERS & $0.5 \cdot 2.0 \mathrm{mF}$ & L1 LAS, 12 LRS, CAS & 2 \\
\hline & REED SOL OHON/COWN Decoofe & SPACE BASCD & 11 LAS, L2 LAS & $\cdot$ \\
\hline \multirow{14}{*}{ 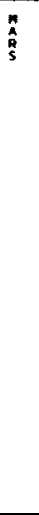 } & KA-DNOW S/C REFLECTOR & $5 \mathrm{~m}, 55 x$ to $36 \mathrm{~m}, 45 x$ & mpr, uns, cas spacecrart & $1-2$ \\
\hline & HECWUICALLY SIEEPABLE AEFLECTOR & $5.9 \mathrm{~m}, 3600$ & WPV, FAS EMATH POINTIME NHTEMAM & 2 \\
\hline & ELEC SWITCHED FIXED BEN ANTEMOM & 20-DECAms & mas mas anterma & $\cdot$ \\
\hline & 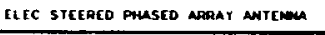 & 20-BEAMES & mas maps antemman & 2 \\
\hline & S/C NIELOA POINTINC & -0.003 deg & mov, ans, cas SPACECRAFT & 2 \\
\hline & Ka, 60, 94, 134 Gix NWTA & $115 \mathrm{~W}, \mathrm{HICH}$ EFF & 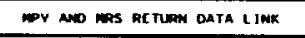 & $1-2$ \\
\hline & KA-WNONO SSPA & $1.10 \%$ & 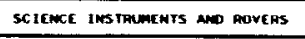 & 2 \\
\hline & wic aevices & LOWER MOISE / hIGHER POAER & ptused aprars ano SSPA & $2-3$ \\
\hline & LON LOSS DE MOOULATOA & $1.5 \%$ & CAS SPACECAAFT & 4 \\
\hline & POUER EFFICIENT MOOULATION & $16-55 x$ & WPV NGO WRS RETURN DATA LIMKS & 2 \\
\hline & BASCENAO PROCESS INC ANO SMITCHINC & ACTS ERUIVALENT & mov, mas, cas spacticaAfT & 4 \\
\hline & LOW MOISE RECEIVERS & $0.50\left(K_{2}\right)$ 10 $2.00(134012)$ & GPS SPACECRATT & 1.2 \\
\hline & LOW Lass fEeD Srstem & $0.4 \propto\left(k_{0}\right)$ to $1.5 \propto(134$ OHI $)$ & cos seacficaart & 1 \\
\hline & 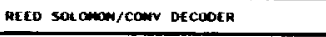 & SPACE QASEO & ces spucecontt & $\cdot$ \\
\hline \multirow{2}{*}{1} & Data compression & 50,1 (Lossn) / 1011 (LossLifss) & YIDEO MO OATA SIOMALS & 2 \\
\hline & OATA STORAGE & 10's Toytes / $1 \operatorname{cops}(\mathrm{R} / \mathrm{N})$ & ALt TWIM moots & 2 \\
\hline
\end{tabular}


Figure 6-1 Technology Program Planning Timeline

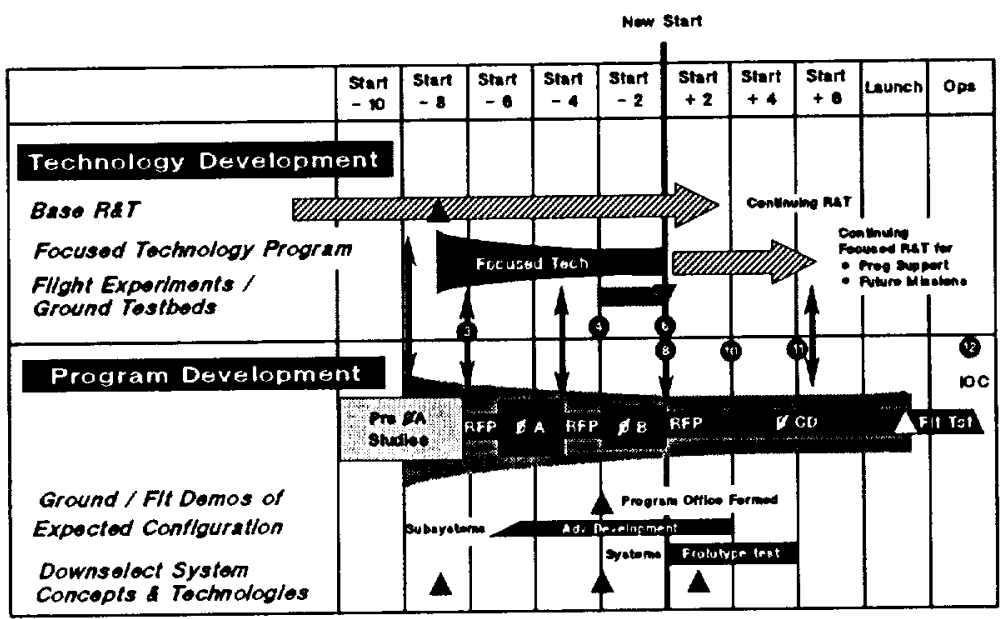

Figure 6-2 Representative TWT Development Schedule

Figure 6-3 Representative SSPA Development Schedule

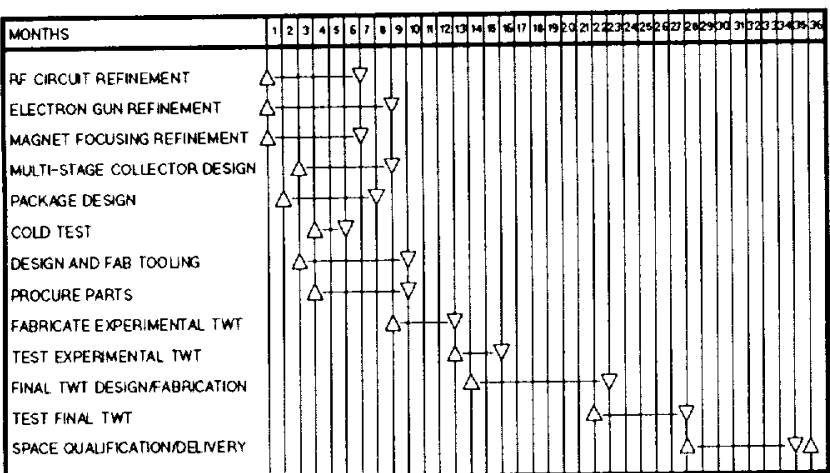

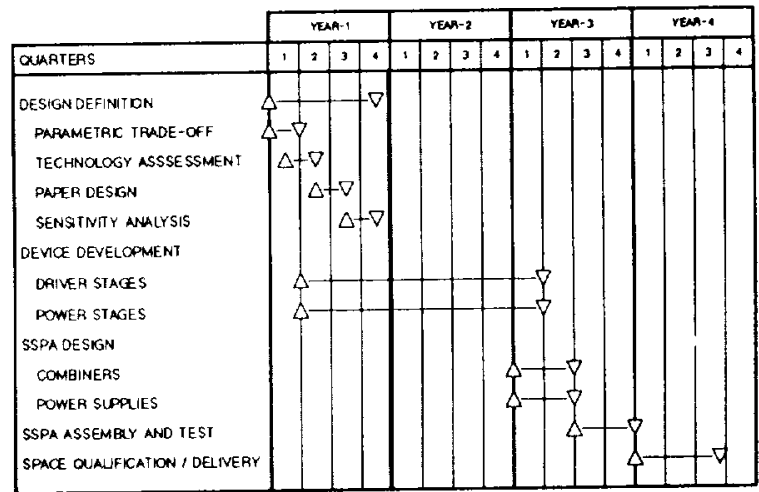

TABLE 6-1

EXAMPLE ARCHITECTURE TRADES TIMELINE

\begin{tabular}{|l|c|c|c|c||}
\hline \multicolumn{1}{|c|}{ ARCHITECTURE } & $\begin{array}{c}\text { FIRST HUMANS } \\
\text { ON MOON }\end{array}$ & $\begin{array}{c}\text { FIRST HUMANS } \\
\text { ON MARS }\end{array}$ & $\begin{array}{c}\text { FIRST } \\
\text { OUTPOST ON } \\
\text { MOON }\end{array}$ & $\begin{array}{c}\text { FIRST } \\
\text { OUTPOST } \\
\text { ON MARS }\end{array}$ \\
\hline \hline EXPLORATION EMPHASIS & 2000 & 2006 & 2010 & 2014 \\
\hline EXPANDING HUMAN PRESENCE & 2002 & 2012 & 2002 & 2012 \\
\hline AGGRESSIVE MARS ARCHITECTURE & 2008 & 2004 & 2008 & 2014 \\
\hline MODIFIED REFERENCE ARCHITECTURE & 2001 & 2012 & 2003 & 2012 \\
\hline ENERGY ENTERPRISE & 2005 & 2019 & 2005 & 2021 \\
\hline
\end{tabular}

TABLE 6-2

SUMMARY OF TECHNOLOGY DEVELOPMENT STARTUP DATES FOR MOON AND MARS MISSIONS

\begin{tabular}{|l|c|c|}
\hline & $\begin{array}{c}\text { MOON MISSION } \\
\text { TECHNOLOGIES }\end{array}$ & $\begin{array}{c}\text { MARS MISSION } \\
\text { TECHNOLOGIES }\end{array}$ \\
\hline \hline OPTION 1 & 1992 & 1996 \\
\hline OPTION 2 & 1992 & 1991 \\
\hline OPTION 3 & 1991 & $1995-96$ \\
\hline OPTION 4 & 1991 & $1995-96$ \\
\hline
\end{tabular}




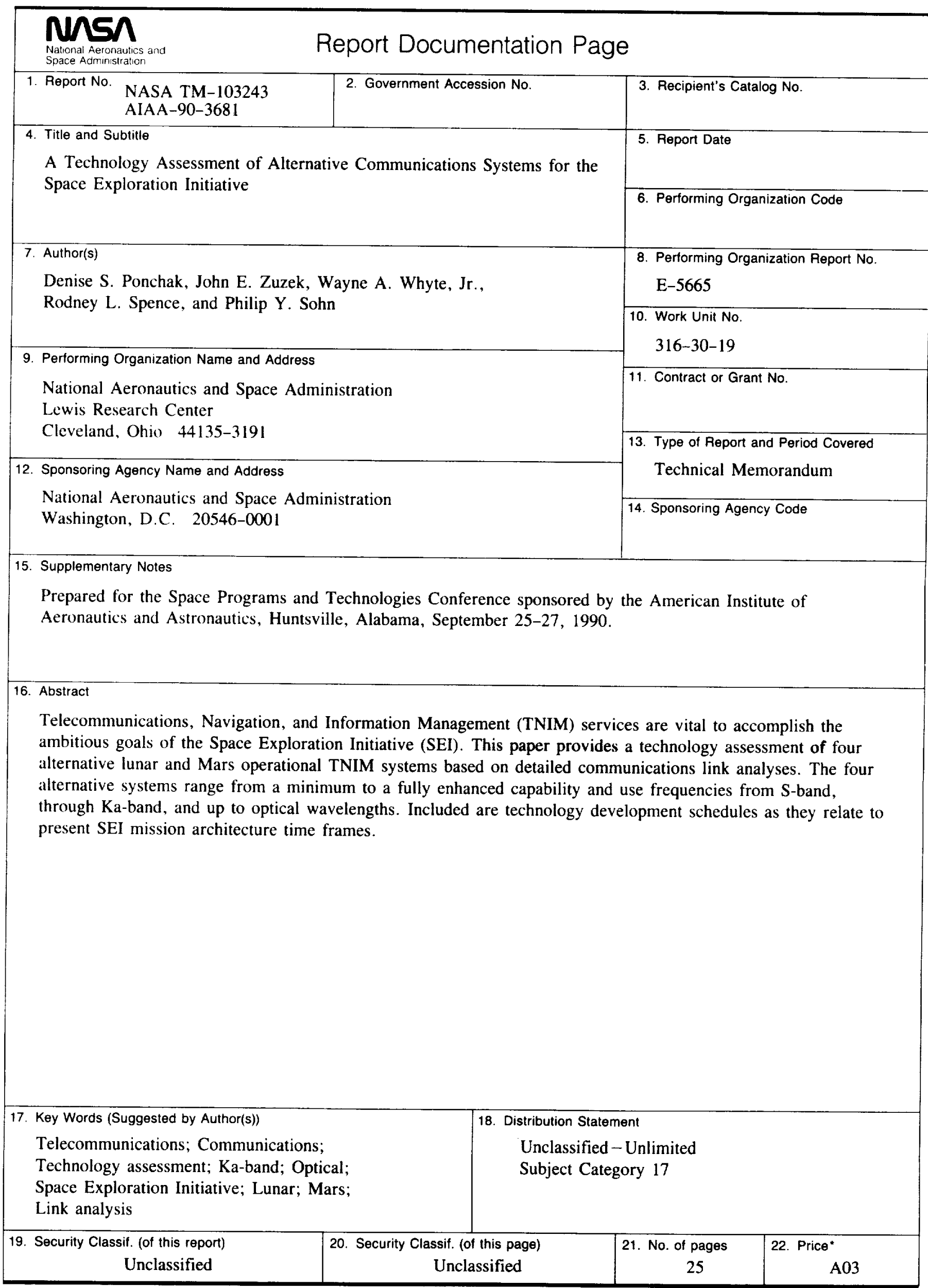



National Aeronautics and Space Administration

Lewis Research Center.

Cleveland, Ohio 44135

Official Business

Penalty for Private Use $\mathbf{5 3 0 0}$

FOURTH CLASS MAIL

ADDRESS CORRECTION REQUESTED
|||| $\mid$

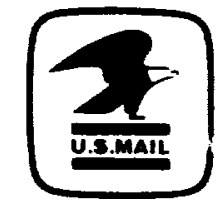

Postage and fres Pa:

Natorial Aeronetules and

wigar Adininicite dtw

I.A.SA 451 